\title{
As geleiras carboníferas no sul do Brasil
}

\author{
The Carboniferous glaciers in southern Brazil
}

\author{
EDUARDO DA ROSA ${ }^{1}$, FERNANDO VESELY ${ }^{2}$, JOHN ISBELL $^{3} \&$ NICHOLAS FEDORCHUK $^{4}$ \\ ${ }^{1}$ University of Wisconsin-Milwaukee (UWM), Milwaukee, WI, Estados Unidos da América do Norte, menozzo2@uwm.edu \\ ${ }^{2}$ Universidade Federal do Paraná (UFPR), Curitiba, Paraná, Brasil, vesely@ufpr.br \\ ${ }^{3}$ University of Wisconsin-Milwaukee (UWM), Milwaukee, WI, Estados Unidos da América do Norte, jisbell@uwm.edu \\ ${ }^{4}$ Southern Connecticut State University, New Haven, CT, Estados Unidos da América do Norte, fedorchukn1@southernct.edu
}

\begin{abstract}
Resumo
A Era Glacial Neopaleozoica (362 a $256 \mathrm{Ma}$ ) deixou um registro nas bacias sedimentares Gondwânicas na forma de depósitos e feições erosivas glaciogênicas. A glaciação é registrada na Bacia do Paraná nos estratos do Grupo Itararé e em sua discordância basal caracterizada por diversas estruturas erosivas. Estruturas erosivas, como superfícies estriadas, e diamictitos são amplamente empregados tanto na caracterização de aspectos paleoglaciológicos como na definição do paleofluxo de geleiras e suas áreas-fontes. Entretanto, superfícies estriadas também são geradas por quilhas de icebergs, assim como diamictitos são gerados por outros processos não-glaciais. No sul do Brasil, o avanço das geleiras carboníferas esculpiu diferentes feições sobre o embasamento do Grupo Itararé, sendo interpretadas como produto de diferentes cenários de glaciação. No Paraná, geleiras não confinadas e de base plana avançaram predominantemente sobre arenitos devonianos da Formação Furnas. Em Santa Catarina, o avanço de geleiras sobre terrenos ígneos e metamórficos resultou em uma discordância de topografia muito irregular que sugere a presença de corredores de gelo. No Rio Grande do Sul, uma série de paleovales glaciais são interpretados como o produto da ação glacial sobre o escudo riograndense. Entretanto, há controvérsia sobre o controle tectônico versus glacial na geração destes paleovales. O estudo detalhado da ação glacial vem refinando o entendimento sobre a complexa glaciação que ocorreu no sul do Brasil durante o Carbonífero.
\end{abstract}

Palavras-chave: Grupo Itararé; Bacia do Paraná; Era Glacial Neopaleozoica; glacial; subglacial

\begin{abstract}
The Late Paleozoic Ice Age (LPIA; 362 to 256 Ma) left a record in the Gondwanan sedimentary basins as glacial successions and ice-carved features. In the Paraná Basin, the glaciation is recorded in the Itararé Group and on its basal unconformity that contains micro to mega scale erosive features. Diamictites and glacial erosive landforms such as striated surfaces have been used to reconstruct past glacial dynamics as well as to define ice kinematics and ice-spreading centers. However, soft-sediment striated surfaces generated by scouring of iceberg keels are also common in the Itararé Group strata as well as diamictites generated by nonglacial processes. Assemblages of erosive landforms left behind by Carboniferous glaciers in southern Brazil are evidence for different glaciation scenarios. In the Paraná State, flat-based, unconfined ice lobes advanced northward over Devonian sandstones of the Furnas Formation. In the Santa Catarina state, the glacial advances are characterized by an irregular topography on igneous and metamorphic basement, probably a result of advancing ice streams. In Rio Grande do Sul, an assemblage of paleovalleys is interpreted as the product of glaciation; however, these valleys could have been generated by tectonism and not by glacial erosion. The complex glacial events that took place in southern Brazil are being better understood due to detailed studies on the record left behind by Carboniferous glaciers.
\end{abstract}

Keywords: Itararé Group; Paraná Basin; Late Paleozoic Ice Age; glacial; subglacial 


\section{Introdução}

Reconfiguração supercontinental e colonização dos continentes por plantas resultaram no período glacial mais extenso e severo do Fanerozoico, onde as concentrações atmosféricas de $\mathrm{CO} 2$ e $\mathrm{O} 2$ atingiram os menores e maiores níveis, respectivamente (Montañez \& Poulsen 2013, Qie et al. 2019). A Era Glacial Neopaleozoica (Late Paleozoic Ice Age; LPIA) iniciou no final do Neodevoniano (Famenniano; $362 \mathrm{Ma}$ ), culminou no Carbonífero-Permiano, e terminou no Neopermiano (Wuchiapingiano; $256 \mathrm{Ma}$ ) (Rosa \& Isbell 2021).

O conceito da LPIA mudou nos últimos anos de uma visão tradicional estática para uma visão mais dinâmica. A visão tradicional assume que o grande "Manto de Gelo Gondwânico" nucleado na Antártica se expandiu sobre grande parte do Gondwana em um contexto de uma única época glacial (Du Toit 1937, Veevers \& Powell 1987, Crowell 1999, Scotese et al. 1999). O atual paradigma da LPIA é de que vários mantos de gelo, calotas de gelo, e campos de gelo de altitude foram nucleados e desapareceram de maneira assíncrona sobre o Gondwana (Isbell et al. 2003, 2012). Além do mais, atualmente são reconhecidos vários episódios glaciais de 1-8 Ma de duração intercalados com episódios interglaciais de similar extensão (Fielding et al. 2008, Montañez \& Poulsen 2013, Rosa \& Isbell 2021). O registro da LPIA está amplamente distribuído pelas bacias sedimentares Gondwânicas em todos os fragmentos do antigo supercontinente: América do Sul, África, Península Arábica, Antárctica, Austrália e sudoeste da Ásia (e.g. Crowell \& Frakes 1975, Caputo \& Crowell 1985, Isbell et al. 2003, Rosa \& Isbell 2021). O registro glacial gerado durante a LPIA compreende feições erosivas de micro a mega escala que embasam sequências predominantemente marinhas depositadas direta ou indiretamente por geleiras durante fases de avanço e recuo glacial (e.g. Visser 1997, Vesely \& Assine 2006, Caputo et al. 2008, Valdez et al. 2019, López-Gamundí et al. 2021).

O Grupo Itararé da Bacia do Paraná consiste em um dos registros mais espessos (até $1300 \mathrm{~m}$ em subsuperfície; França \& Potter 1988) e temporalmente extensos da LPIA. Sua idade deposicional atualmente é estimada entre o Mississippiano Médio (Viseano) e o limite Carbonífero-Permiano (Gzheliano-Asseliano) (e.g. Cagliari et al. 2016, Rosa et al. 2019, Valdez et al. 2019, Souza et al. 2021) ou Eopermiano (Sakmariano) (e.g. Holz et al. 2010, Mottin et al. 2018) (Fig. 1). Várias formações empilhadas que afloram na margem sul e leste da bacia compõem o Grupo Itararé. Duas classificações foram propostas e são amplamente utilizadas, da base para o topo: Campo do Tenente, Mafra e Rio do Sul (Schneider et al. 1974); Lagoa Azul, Campo do Tenente e Taciba (França \& Potter 1988). Proposta mais recente admite ainda a ocorrência de unidades de ambas as classificações na faixa de afloramentos do Paraná (Vesely, et al., 2021; neste volume). Nas bordas oeste e norte da bacia, as formações Aquidauana, Aquidabán e Coronel Oviedo compreendem a sucessão glacial neopaleozoica (Rocha-Campos \& Santos 1981). O Grupo Itararé é essencialmente marinho com influência glacial na sedimentação (Vesely \& Assine 2006, Valdez et al. 2019), onde alguns raros intervalos de pouca continuidade lateral são observados como gerados em contato com geleiras (Vesely et al. 2015, Aquino et al. 2016, Mottin et al. 2018, Fedorchuk et al. 2019a, Rosa et al. 2019).

Desde as primeiras menções aos depósitos glaciais do Grupo Itararé na Bacia do Paraná (e.g. Derby 1878, White 1908), o arcabouço estratigráfico, sequências de-

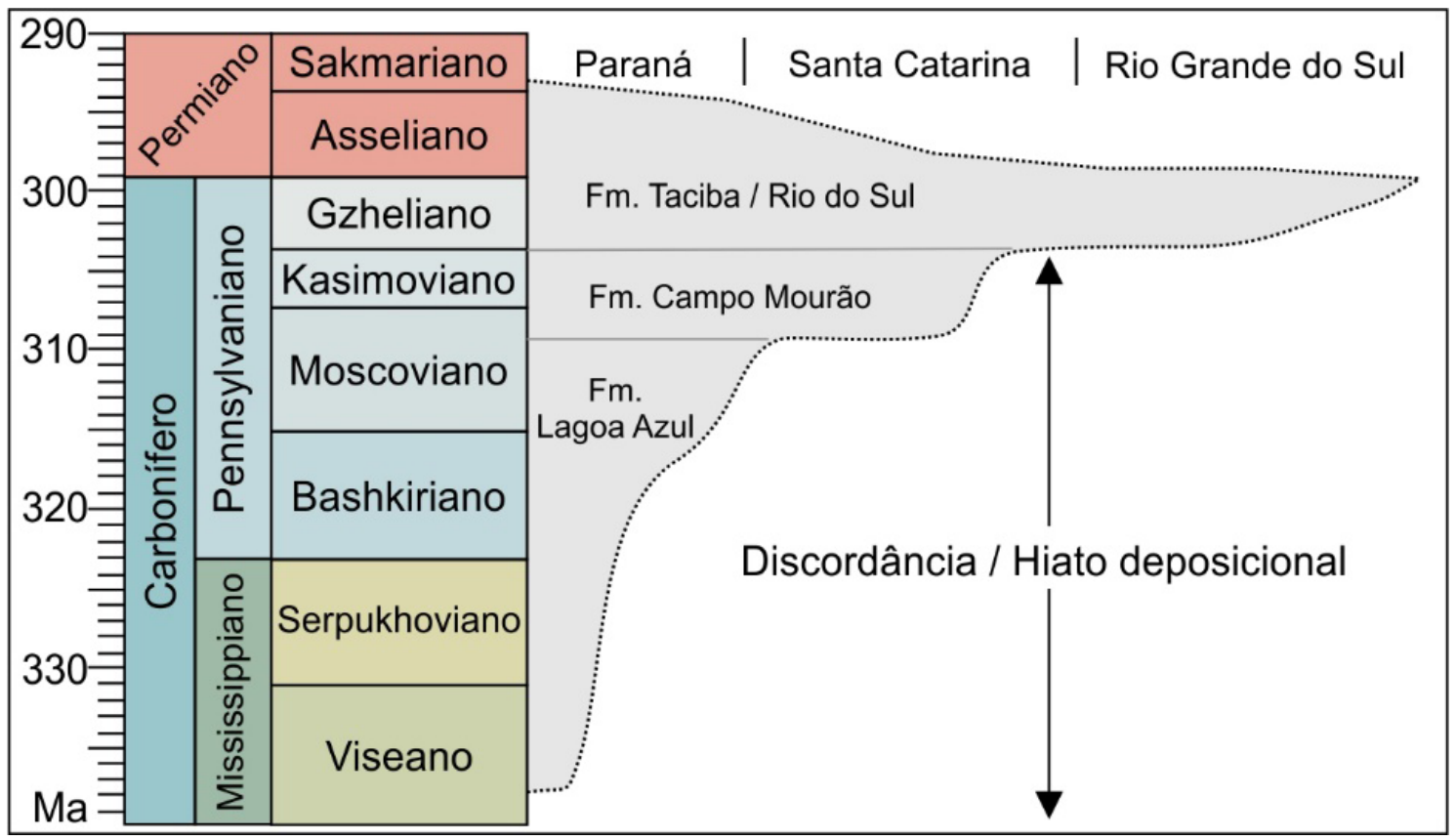

Figura 1 - Carta cronoestratigráfica simplificada do Grupo Itararé no sul do Brasil (adaptado de Holz et al. (2010); idades basais no Paraná de Rosa et al. (2019) e idades no Rio Grande do Sul de Cagliari et al. (2016) e Souza et al. (2021). 
posicionais, idade deposicional, ciclos glaciais, aspectos paleoglaciológicos e paleogeografia glacial do Grupo Itararé vem sendo mais bem detalhados, principalmente na região sul do Brasil. O presente trabalho tem como objetivo contribuir com uma revisão sobre o conhecimento nos seguintes tópicos nos estados do Paraná, Santa Catarina e Rio Grande do Sul: 1) análise das estruturas erosivas e deposicionais atribuídas à ação direta de geleiras documentadas na base do Grupo Itararé; 2) cinemática glacial e aspectos paleoglaciológicos; e 3) área fonte de nucleação das geleiras. Esta revisão é primariamente apresentada a partir de dados bibliográficos, porém também contém a descrição inédita de uma nova feição erosiva de origem glacial.

\section{As geleiras como agentes erosivos e deposicionais}

As formas e estilos de geleiras são função do clima e da topografia, sendo que a morfologia de cada geleira é única. Para propósitos de descrição e estudo de geleiras antigas e atuais é conveniente dividi-las de acordo com seu tamanho, morfologia e relação com a topografia (Bennett \& Glasser 2009). Levando em consideração estas características, geleiras não relacionadas à topografia são classificadas como calota de gelo (ice cap) e manto de gelo (ice sheet), sendo que capas de gelo são menores que $50.000 \mathrm{~km}^{2}$ (Benn \& Evans 2010). Geleiras controladas pela topografia são nucleadas em altas altitudes e fluem topografia abaixo, sendo denominadas de geleiras de vale (valley glaciers) (Benn \& Evans 2010).

Geleiras se movimentam devido à gravidade pelos mecanismos de deformação da camada basal deformante (substrato inconsolidado que virá a ser um tilito subglacial), deformação interna da geleira e por deslizamento basal (Assine \& Vesely 2008, Benn \& Evans 2010) (Fig. 2A). Geleiras são os mais efetivos agentes erosivos, capazes de erodir imensas áreas e escavar vales e até bacias sedimentares. Os mecanismos pelos quais geleiras erodem o substrato são a abrasão e remoção de blocos (plucking ou quarrying). O primeiro mecanismo é o gradual desgaste do substrato por detritos carregados na base das geleiras, já o segundo se dá pela remoção de blocos do substrato rochoso através de fraturas e é o mais efetivo mecanismo de erosão glacial (Assine \& Vesely 2008, Bennet \& Glasser 2009) (Fig. 2B).

$\mathrm{O}$ regime térmico basal das geleiras tem um papel importante na erosão subglacial dado que controlam os principais mecanismos de movimento glacial, velocidade de fluxo e taxas de erosão (Hambrey \& Glasser 2012). Geleiras que possuem regime térmico basal úmido e quente, ou seja, onde a base da geleira está acima do ponto de congelamento, propiciam a presença de água de degelo. Isso facilita a movimentação destas geleiras temperadas por deslizamento basal e, principalmente, por deformação do substrato inconsolidado, o qual está saturado em água. Isto resulta em rápidas velocidades de fluxo e taxas de erosão do substrato. Exemplos de geleiras temperadas ocorrem nos Alpes, Alaska e Patagônia. Já em geleiras de base seca e fria, como as geleiras polares da Antártica, a ausência de água de degelo na base da geleira inibe movimentação por deslizamento basal e deformação do substrato inconsolidado; portanto a geleira se move principalmente por deformação interna. Isto resulta em baixa velocidade de fluxo e consequentemente baixa efetividade para erodir o substrato o qual as geleiras estão avançando. Ainda, algumas geleiras de vale modernas possuem um complexo regime térmico basal misto (politermal), onde diferentes zonas da base da geleira estão acima ou abaixo do ponto de congelamento, por exemplo as geleiras polares de Svalbard (Hambrey \& Glasser 2012).

Além do regime térmico basal, a natureza do substrato rochoso o qual a geleira avança também controla a geração de diferentes tipos de feições erosivas e a natureza plana ou ondulada da superfície erodida pela geleira (Rea \& Evans 1996). Influências do substrato na geração de feições glaciais incluem a composição litológica do substrato e a presença, orientação e densidade de descontinuidades primárias e secundárias como estratificação, foliação e fraturas (Phillips et al. 2010, Krabbendam \& Glasser 2011).

Como resultado da combinação do regime térmico basal e morfologia das geleiras, bem como a natureza do substrato, diferentes tipos e tamanhos de feições erosivas ficam registradas após a passagem das massas de gelo.
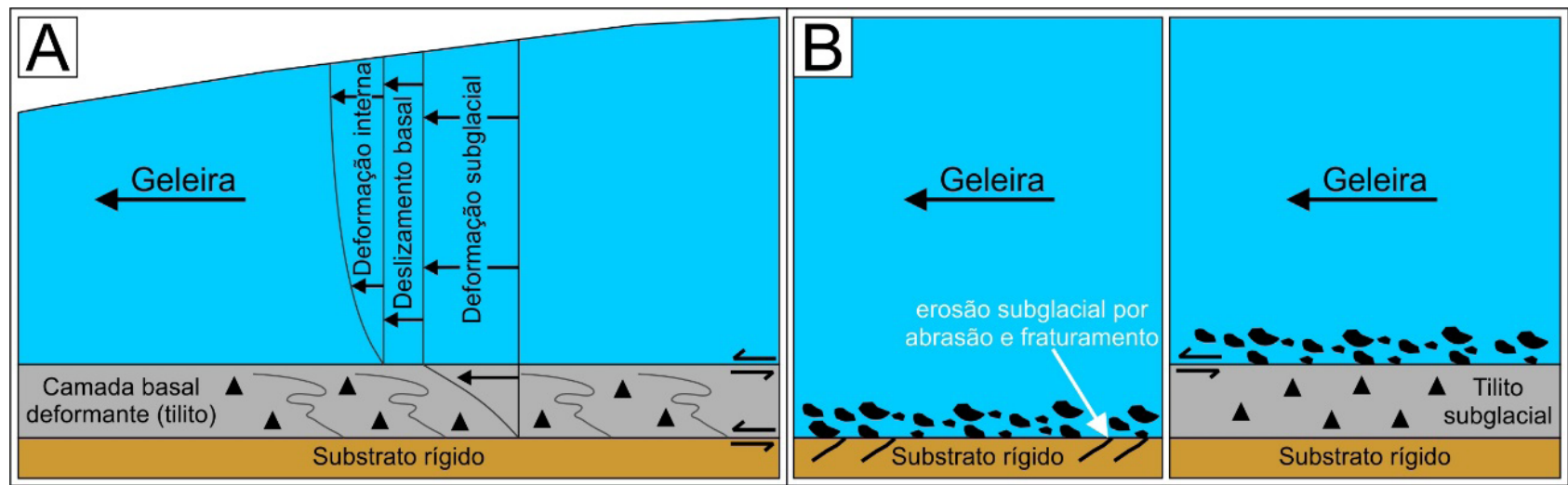

Figura 2 - Interação das geleiras com o substrato. A) Processos de movimentação glacial e suas taxas relativas de movimento (adaptado de Bennett \& Glasser (2009)). B) Cenários da zona subglacial com geleira em contato direto com o substrato e geleira sobre a camada basal deformante (tilito subglacial). Adaptado de Hart (1995). 


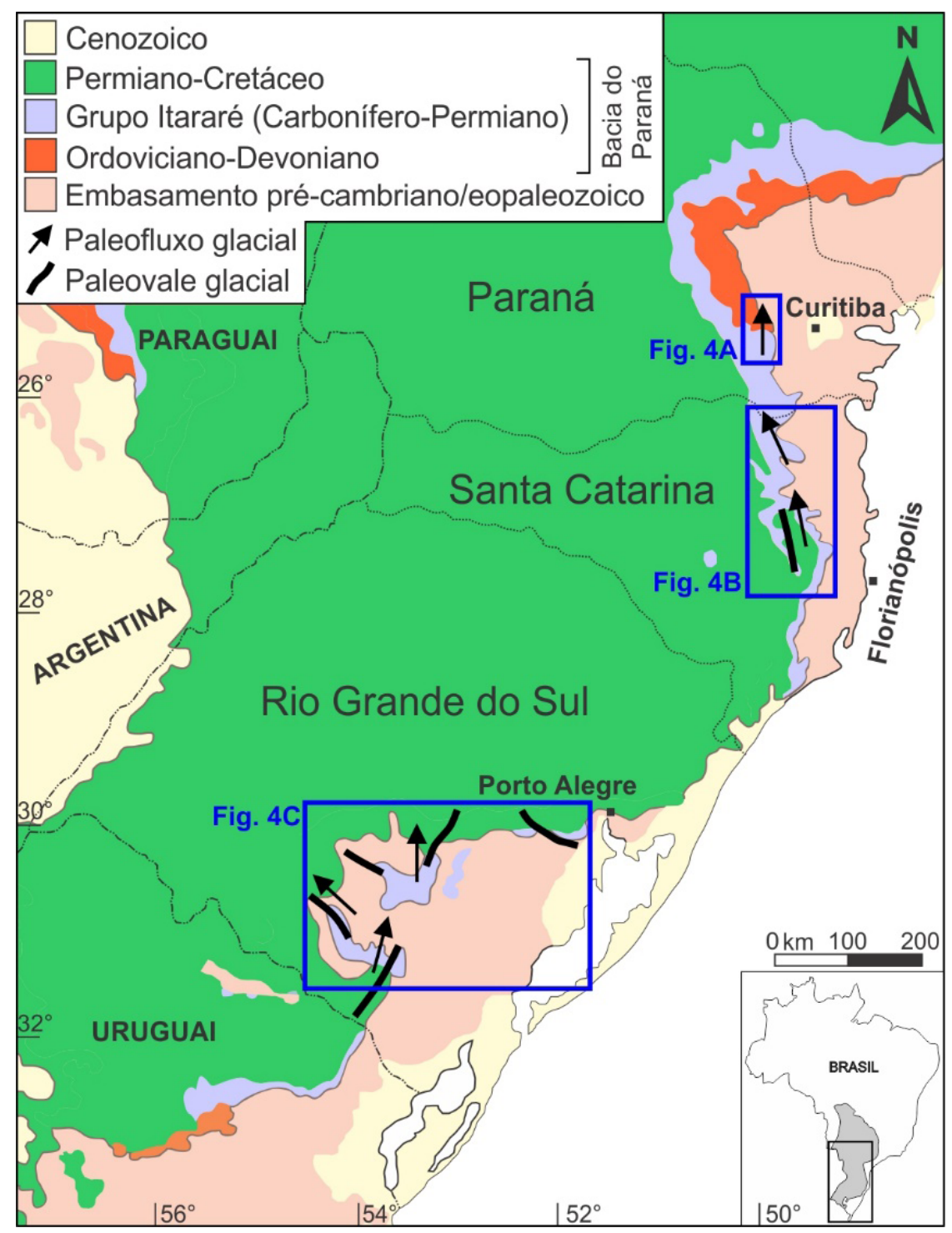

Figura 3 - Mapa geológico simplificado da Bacia do Paraná no sul do Brasil mostrando as principais direções de paleofluxo glacial obtidas por superfícies estriadas e os paleovales glaciais na discordância basal do Grupo Itararé. Localidades, detalhamento dos tipos de estruturas glaciogênicas e referências são apresentados na Tabela 1.

Feições erosivas variam desde pequena a média escala (e.g. superfícies polidas, sulcadas e estriadas, formas alongadas moldadas no substrato) até regiões inteiramente denudadas por massas de gelo, como os inúmeros vales glaciais da Patagônia ou a superfície glacial aplainada distribuída por quase todo o Canadá (Sugden 1978, Benn \& Evans 2010, Darvill et al. 2016).

Ao passo que uma geleira em movimento erode o substrato, os sedimentos gerados vão sendo incorporados na base da geleira, na zona subglacial, gerando uma camada basal de sedimentos entre a geleira e o substrato (Fig. 2B). Esta camada é gerada por vários processos que ocorrem concomitantemente na zona subglacial, tais como: fusão e degelo na base da geleira, alojamento de detritos em irregularidades no substrato, deposição por fluxos de água de degelo e, principalmente, deformação (Boulton et al. 2001, Evans et al. 2006, Evans 2018). Evidência para a maioria destes processos é obliterada devi- do à constante deformação da camada pela pressão gerada pelo peso da geleira em avanço. O resultado é uma camada maciça, homogênea e muito mal selecionada contendo detritos de vários tamanhos dispersos em uma matriz lamosa ou arenosa (Hart 1995, van der Meer et al. 2003, Phillips 2018). Texturalmente, este produto é classificado como um diamictito. O termo tilito subglacial é uma denominação de cunho genético e deve ser usado somente quando suportado por evidências de sua gênese zona subglacial (Fig. 2). Tilitos subglaciais possuem um baixo potencial de preservação dados os subsequentes processos erosivos operantes durante a deglaciação e, consequentemente, são raros no registro estratigráfico. Em contrapartida, diamictitos são gerados por vários outros processos, como fluxos de detritos e deslizamentos subaquáticos (Crowell 1957, Boulton \& Deynoux 1981, Visser et al. 1984, Dykstra et al. 2011, Sobiesiak et al. 2018, Vesely et al. 2018, Rodrigues et al. 2021; neste vo- 


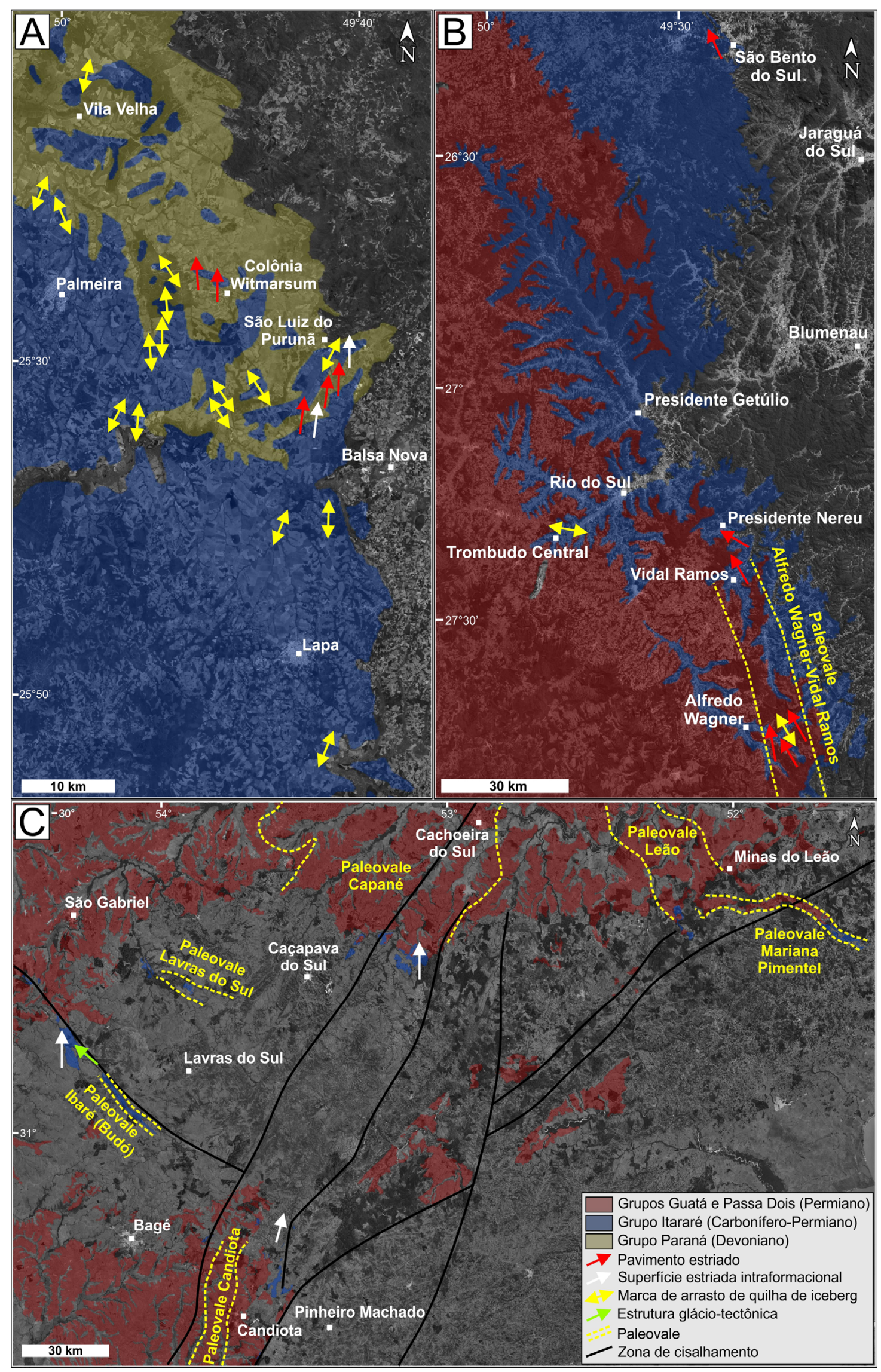

Figura 4 - Mapas geológicos mostrando a ocorrência de estruturas erosivas geradas pelo gelo e sentido de paleofluxo glacial em A) Paraná; B) Santa Catarina; C) Rio Grande do Sul. Imagens do GoogleEarth, unidades litoestratigráficas da CPRM (1:1.000.000), zonas de cisalhamento de Tedesco et al. (2019). Referências de estruturas glaciais na Tabela 1. 
lume). Diamictitos gerados por esses processos não glaciais são muito mais comuns do que tilitos subglaciais no registro estratigráfico (Eyles \& Eyles 2010).

\section{O registro glacial da Bacia do Paraná no sul do Brasil}

A primeira menção sobre estruturas erosivas glaciais na Bacia do Paraná foi em 1940 (Barbosa 1940, Carvalho 1940). Desde então, o acervo de feições erosivas de micro a mega escala vem sendo incrementado (Figs. 3 e 4, Tab. 1), principalmente no contato basal do Grupo Itararé com as unidades que foram submetidas à erosão subglacial durante avanços glaciais na $L P I A$. Estas unidades incluem terrenos metamórficos e ígneos precambrianos a eopaleozoicos, bacias transicionais eopaleozoicas e unidades devonianas da Bacia do Paraná (Fig. 3).

O contato basal do Grupo Itararé é uma discordância gerada por erosão glacial e sobre esta discordância ocorrem estratos de diferentes idades (Fig. 1). Estratos mais antigos do Grupo Itararé ocorrem somente no Paraná e nos estados a norte do Paraná. Em Santa Catarina e Rio Grande do Sul somente as formações mais jovens do Grupo Itararé estão presentes (França \& Potter 1988, Santos et al. 1996, Holz et al. 2010). O registro mais antigo do Grupo Itararé ocorre na região de Balsa Nova (PR) e é datado por palinologia como Mississippiano Médio (Viseano) (Rosa et al. 2019). Estratos mais jovens imediatamente sobre a discordância foram depositados no Pennsilvaniano Superior (Moscoviano-Kasimoviano; $\sim 307 \mathrm{Ma}$ ) (Cagliari et al. 2016). Esta idade foi obtida a partir de datação radiométrica em estratos do topo do Grupo Itararé na região de Cachoeira do Sul no Rio Grande do Sul. A ausência de datações diretas para a idade da discordância basal do Grupo Itararé não permite inferir seguramente se a discordância é sincrônica ou diacrônica. Ou seja, se a discordância em diferentes regiões foi gerada ao mesmo tempo (sincrônica) e os estratos sobrepostos foram depositados em tempos diferentes, ou se a discordância foi gerada durante tempos diferentes (diacrônica) e os estratos sobrepostos foram depositados logo após a erosão.

A compilação de estruturas erosivas relacionadas ao gelo nas porções basais do Grupo Itararé na região sul do Brasil é apresentada na Tabela 1. Com exceção da superfície estriada de Presidente Nereu (Santa Catarina), a qual é descrita pela primeira vez neste trabalho, as outras estruturas foram compiladas de trabalhos já publicados. Cinco principais categorias de estruturas são identificadas e aqui discutidas:

1. Pavimentos estriados: superfícies horizontais ou com mergulho, por vezes polidas, contendo sulcos e estrias paralelas. Representam erosão subglacial por abrasão sobre substrato rígido.

2. Formas alongadas moldadas no substrato (streamlined landforms): estruturas de topografia positiva alongadas na direção do fluxo glacial e geradas por abrasão e remoção de blocos. Compreendem roches mountonnées, whalebacks, entre outras formas. Geralmente estão associadas a depressões alongadas entre duas formas alongadas adjacentes.

\begin{tabular}{|c|c|c|}
\hline Referência & Localidade & Estrutura glacial \\
\hline \multicolumn{3}{|c|}{ PARANÁ } \\
\hline Bigarella et al. (1967) & Colônia Witmarsum & Pavimento estriado \\
\hline Trosdtorf et al. (2005a) & São Luiz do Purunã & Superfície estriada intraformacional \\
\hline Vesely (2006) & Colônia Witmarsum & Pavimento estriado \\
\hline Vesely \& Assine (2014) & Lapa, Vila Velha, Palmeira e São Luiz do Purunã & Marcas de arrasto de quilha de iceberg \\
\hline Rosa et al. (2019) & Balsa Nova & Pavimentos estriados \\
\hline Rosa et al. (2019) & Balsa Nova & Superfície estriada intraformacional \\
\hline Rosa et al. (2019) & Balsa Nova & Marcas de arrasto de quilha de iceberg \\
\hline \multicolumn{3}{|c|}{ SANTA CATARINA } \\
\hline Barbosa (1940); Carvalho (1940) & São Bento do Sul & Pavimento estriado \\
\hline Santos et al. (1992) & Trombudo Central & Marca de arrasto de quilha de iceberg \\
\hline Rocha-Campos et al. (1988) & Alfredo Wagner & Pavimento estriado \\
\hline Carvalho (2014); Puigdomenech et al. (2014) & Vidal Ramos & Pavimento estriado e paleovale glacial \\
\hline Rosa et al. (2016) & Vidal Ramos & Forma alongada moldada no substrato \\
\hline Fallgatter \& Paim (2019) & Alfredo Wagner & Pavimentos estriados e paleovale glacial \\
\hline Este trabalho & Presidente Nereu & Superfície estriada intraformacional \\
\hline \multicolumn{3}{|c|}{ RIO GRANDE DO SUL } \\
\hline Mau (1960) & Lavras do Sul - Ibaré & Paleovale glacial \\
\hline Mau (1960) & Lavras do Sul & Paleovale glacial \\
\hline Tomazelli \& Soliani (1982) & Cachoeira do Sul & Superfície estriada intraformacional \\
\hline Tomazelli \& Soliani (1982) & Pinheiro Machado & Superfície estriada intraformacional \\
\hline Lopes (1995) & Minas do Leão & Paleovale glacial \\
\hline Lopes (1995) & Cachoeira do Sul - Capané & Paleovale glacial \\
\hline Dias (1993); Holz (1999) & Candiota & Paleovale glacial \\
\hline Tomazelli \& Soliani (1997) & Ibaré & Superfície estriada intraformacional \\
\hline Tedesco et al. (2016) & Mariana Pimentel & Paleovale glacial \\
\hline
\end{tabular}

Tabela 1 - Estruturas erosivas relacionadas ao gelo no sul do Brasil. 
3. Superfícies estriadas intraformacionais (soft-sediment striated surfaces): superfície gerada na interface da base da geleira com o topo da camada basal deformante (tilito) através de ploughing (arado) subglacial. Contém sulcos, estrias, cristas e flutes paralelas ao fluxo glacial.

4. Paleovales glaciais: depressões geradas em substrato rígido através de erosão por geleiras e preenchidas por sedimentos glaciais. Podem ser profundos e estreitos, representando erosão por geleiras de vale (valley glaciers) e denominados fiordes quando estas geleiras terminam no oceano; rasos e amplos, denominados calhas glaciais (glacial troughs) e gerados por corredores de gelo (ice streams) que fluem mais rapidamente do que as geleiras nas suas adjacências.

5. Marcas de arrasto de quilha de iceberg (iceberg-keel scour marks): estruturas geradas sobre sedimento inconsolidado por quilhas de gelo flutuante, geralmente icebergs, porém também por gelo marinho ou lacustre.

As quatro primeiras categorias são geradas por erosão subglacial e são discutidas juntamente para cada estado do sul do Brasil. Marcas de arrasto de quilha de icebergs não são geradas por geleiras e são apresentadas em uma seção especial devido à suas implicações em interpretações paleoambientais e paleogeográficas.

\subsection{Paraná: erosão e deposição por lobos glaciais}

No estado do Paraná, pavimentos estriados são identificados somente sobre arenitos devonianos da Formação Furnas na região de São Luiz do Purunã e Colônia Witmarsum, pertencentes aos municípios de Balsa Nova e Palmeira, respectivamente (Fig. 4A). O clássico pavimento estriado da Colônia Witmarsum descrito por Bigarella et al. (1967), atualmente cadastrado como sítio de interesse geológico, possui sulcos e cristas paralelos formando uma superfície levemente ondulada. A orientação destas formas indica um fluxo glacial para $\mathrm{N}\left(358^{\circ}\right)$. Diretamente sobre o pavimento ocorre um diamictito arenoso maciço interpretado como um tilito subglacial. Aproximadamente $7 \mathrm{~km}$ a noroeste do pavimento, no centro da Colônia Witmarsum, ocorre um pavimento estriado similar. Porém, este possui uma maior amplitude e espaçamento entre sulcos e cristas. Nesta localidade, um diamictito maciço arenoso de até $2,5 \mathrm{~m}$ de espessura ocorre sobre o pavimento e seu topo é parcialmente truncado por arenitos (Vesely 2006).

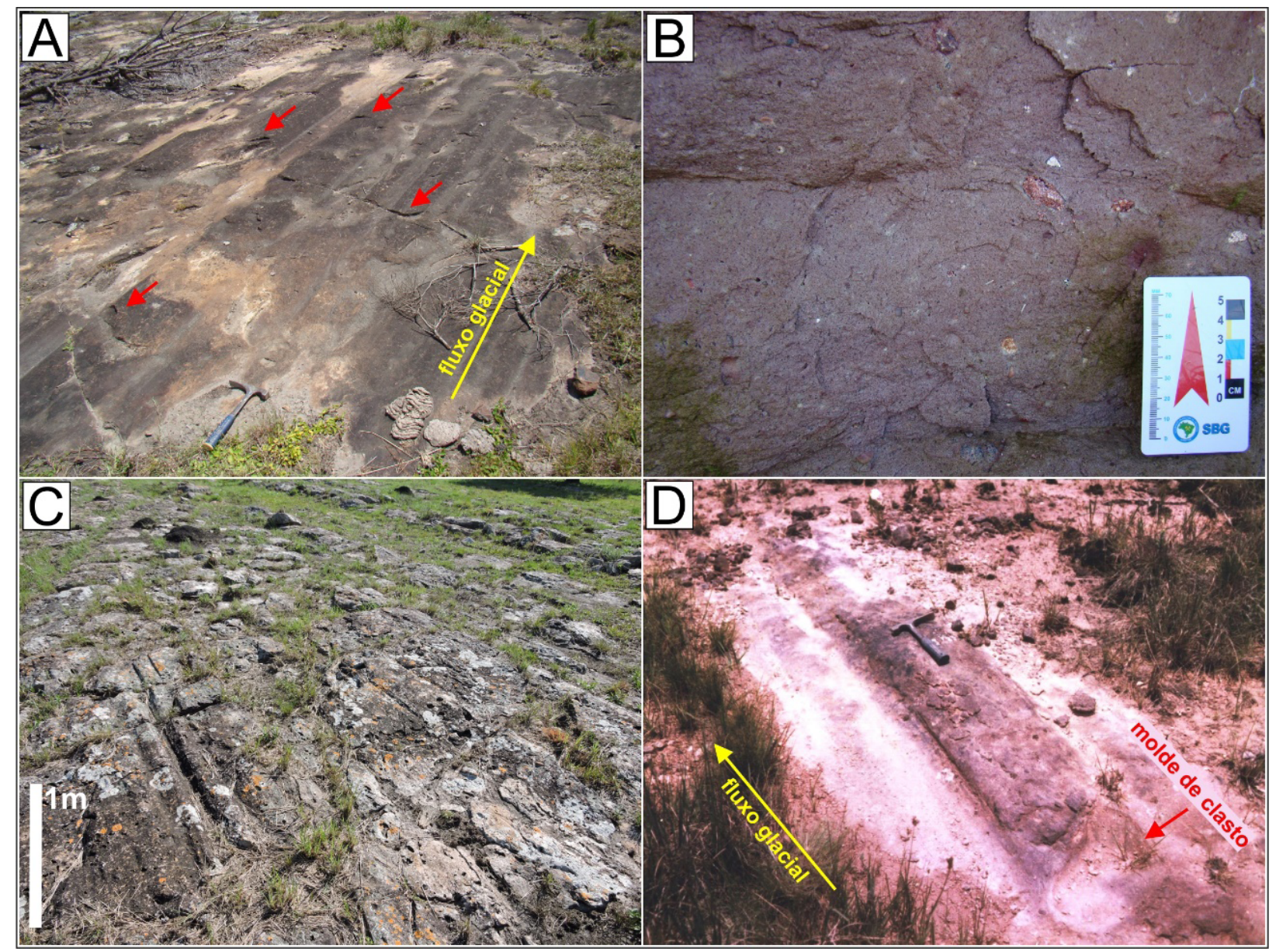

Figura 5 - Formas de erosão glacial no Paraná. A) Pavimento estriado sobre arenitos da Formação Furnas na fazenda do Clube Thalia. Setas vermelhas indicam sulcos em crescente. B) Diamictito maciço interpretado como tilito subglacial sobre o pavimento da Colônia Witmarsum. C) Superfície estriada intraformacional contendo sulcos e cristas ao longo do Rio das Mortes. D) Superfície estriada intraformacional cerca de São Luiz do Purunã contendo uma flute em meio a dois sulcos. 
Três outras ocorrências de pavimentos estriados ao longo do Rio das Mortes em Balsa Nova (PR) possuem uma direção de fluxo glacial para NNE $\left(6^{\circ}\right.$ a $\left.10^{\circ}\right)$ (Rosa et al. 2019). Dentre estes, o pavimento mais proeminente está localizado na sede da fazenda da Sociedade Thalia (Fig. 5A). O pavimento ocorre em uma superfície plana e horizontal de $2.500 \mathrm{~m}^{2}$ e consiste em sulcos largos sobre arenitos da Formação Furnas. Além dos sulcos paralelos, este pavimento contém sulcos em crescente (crescentic gouge), resultantes de fraturamento devido à impactos de clastos na base da geleira contra o substrato rígido.

Diamictitos maciços são encontrados em várias localidades na região de Palmeira e Balsa Nova e sua máxima espessura é estimada em até $7 \mathrm{~m}$ (Fig. 5B). Quando preservado, o topo dos diamictitos apresenta superfícies estriadas intraformacionais. Duas superfícies foram reconhecidas cerca de São Luiz do Purunã e ao longo do Rio das Mortes, ambas evidenciando fluxo glacial para N (Trosdtorf et al. 2005a, Vesely et al. 2015, Rosa et al. 2019) (Fig. 5C).
Estas superfícies contêm sulcos profundos sobre o diamictito, além de apresentarem flutes, que são acumulações de sedimento alongadas à jusante de um clasto (Benn \& Evans 2010) (Fig. 5D). Neste tilito subglacial também foram descritos e medidos planos de cisalhamento subhorizontais, interpretados como produto de deformação subglacial que sugerem movimentação do gelo para NNW.

Resumindo, a orientação dos pavimentos estriados sobre a Formação Furnas e das superfícies estriadas intraformacionais sugerem uma geleira avançando para $\mathrm{N}$ nessa região do Paraná (Figs. 3 e 4A). A pequena variação para NNW e NNE sugere uma distribuição levemente radial quando vista em mapa. A espessura de até $7 \mathrm{~m}$ de tilitos subglaciais é sugestiva de deposição na zona subglacial próximo às margens da geleira. Estas características são sugestivas do avanço de uma geleira não confinada pela topografia, possivelmente terrestre $\mathrm{e}$ de base úmida, sobre uma superfície relativamente plana (Rosa et al. 2019).

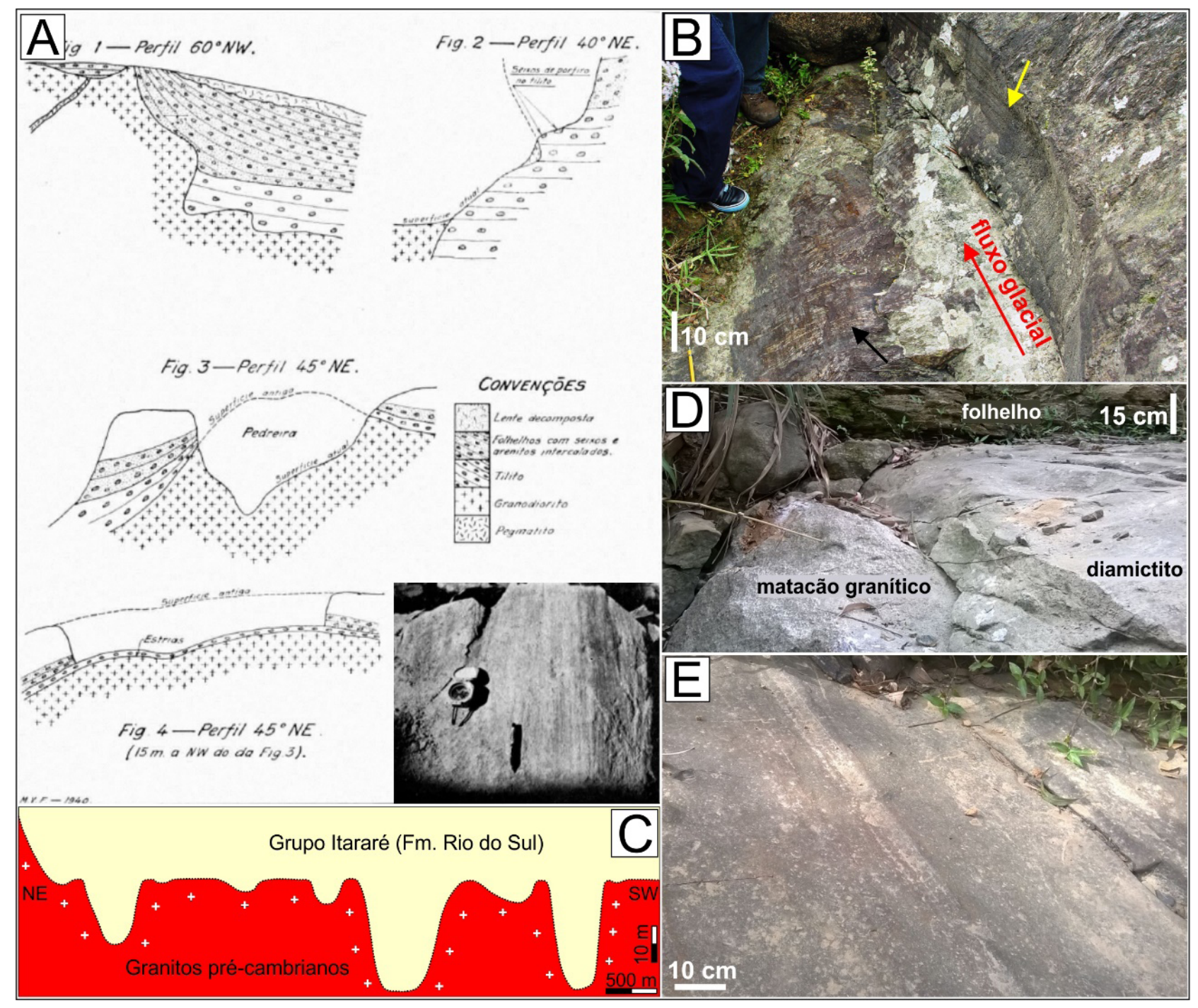

Figura 6 - Feições de erosão glacial em Santa Catarina. A) Desenhos originais e fotografia da superfície estriada de São Bento do Sul (retirado de Barbosa (1940) e Carvalho (1940)). B) Parede (seta amarela) e base (seta preta) de um sulco polido e estriado em Vidal Ramos. C) Esquema simplificado de Fallgatter \& Paim (2019) mostrando a morfologia irregular da discordância glacial contendo sulcos e calhas internos a uma calha maior de $8 \mathrm{~km}$ de comprimento. D e E) Superfície sulcada sobre diamictito subglacial na comunidade de Blinha em Presidente Nereu. 
Sobre este tilito subglacial, há uma complexa sucessão gerada em contato com o gelo devido a dois ciclos de avanços e recuos de geleiras para SW e NW. No geral, as fácies foram geradas em um ambiente marinho raso em zonas proximais a distais de sistemas de leques de deglaciação (outwash fans). Estas sucessões foram posteriormente deformadas por avanços glaciais dando origem a morenas de empurrão e tilitos subglaciais. Os avanços glaciais para $\mathrm{N}$, SW e NW nesta região no sudeste do Paraná geraram este complexo glácio-tectônico que registra a ação das geleiras mais antigas na Bacia do Paraná (Vesely et al. 2015, Rosa et al. 2019, Garcia et al. 2021; neste volume).

\subsection{Santa Catarina: geleiras com bases irregulares}

Barbosa (1940) e Carvalho (1940) descreveram a primeira feição erosiva glacial da Bacia do Paraná. Em uma pedreira atualmente desativada no município de São Bento do Sul, foi descrita uma superfície pequena sobre granodioritos contendo estrias orientadas para NW $\left(335^{\circ}\right)$ (Fig. 6A). Ademais, foram observadas depressões e escavações laterais no granodiorito preenchidas por estratos glácio-marinhos do Grupo Itararé, assim como protuberâncias no embasamento onde os estratos se encontravam moldados de acordo com a morfologia irregular do topo do granodiorito.

Em Vidal Ramos, estrias orientadas segundo $345^{\circ}$ ocorrem em uma superfície polida sobre rochas do embasamento cristalino (Fig. 4B). Esta superfície estriada ocorre na parede e na base de um sulco de aproximadamente $1 \mathrm{~m}$ de profundidade (Fig. 6B). É interpretada como tendo ocorrido na base de um paleovale glacial amplo (12 km de largura) e raso (80 $\mathrm{m}$ de profundidade), caracterizado por paredes inclinadas $10^{\circ}$ a $15^{\circ}$ e que contém sucessões de folhelhos negros e turbiditos no seu interior (Carvalho 2014, Puigdomenech et al. 2014).

Fallgatter \& Paim (2019) trouxeram novas ideias sobre a natureza da discordância basal do Grupo Itararé através de estudos na região de Alfredo Wagner. Previamente nesta região, havia sido descrito um pavimento estriado de pequena dimensão contendo estrias pobremente desenvolvidas e fraturas de fricção que indicam um movimento da geleira para $327^{\circ}$ (Rocha-Campos et al. 1988). Fallgatter \& Paim (2019) documentaram duas novas superfícies estriadas, sendo que a superfície no Rio Lessa é uma parede estriada de uma depressão com estrias e sulcos horizontais entalhadas em granitos. A morfologia do relevo é bastante irregular, contendo depressões lineares desde profundas (até $40 \mathrm{~m}$ ) e largas (até $560 \mathrm{~m}$ ) até rasas (até $8 \mathrm{~m}$ ) e estreitas (até $15 \mathrm{~m}$ ) separadas por protuberâncias no embasamento (formas alongadas moldadas no substrato) (Fig. 6C). Depressões e protuberâncias são alongadas na direção do fluxo glacial e representam uma superfície glacial irregular entalhada sobre o embasamento granítico que condicionou a deposição dos estratos durante a deglaciação. Fallgatter \& Paim (2019) discutem que esta topografia irregular consiste na base de um uma calha glacial de $8 \mathrm{~km}$ de largura, orientada para NNW e que foi entalhada por um corredor de gelo (ice stream). Este vale possivelmente estaria conectado ao paleovale de Vidal Ramos, situado aproximadamente 35 km a NNW, dadas similaridades na orientação de estrias glaciais e similaridade na distribuição de sucessões que ocorrem confinadas aos vales (Fig. 4B).

Irregularidades na topografia da discordância como as descritas acima também foram observadas e mencionadas em outras localidades. Barbosa (1940), Rocha-Campos et al. (1988) e Rosa et al. (2016) mencionam protuberâncias e depressões no topo do embasamento nas regiões de Braço do Norte, São Bento do Sul e Vidal Ramos, respectivamente. Estas irregularidades representam sulcos e formas alongadas moldadas no substrato geradas por erosão na base de geleiras.

Tilitos subglaciais no estado de Santa Catarina são raramente descritos e ocorrem somente na base de pequenas depressões onde detritos subglaciais tendem a ser acumulados e mais bem preservados. Tilitos subglaciais descritos em Alfredo Wagner contêm clastos angulares do embasamento granítico, são delgados e ocorrem irregularmente somente na base dos sulcos (Rocha-Campos et al. 1988, Fallgatter \& Paim 2019). Em São Bento do Sul, clastos angulares do mesmo material do embasamento abaixo ocorrem em tilitos subglaciais também confinados em depressões (Rosa et al. 2016).

Em um córrego a leste do município de Presidente Nereu, na localidade de Blinha $\left(27^{\circ} 17^{\prime} 38.20^{\prime \prime} \mathrm{S} /\right.$ $49^{\circ} 21^{\prime} 56.57^{\prime}$ 'W), aqui é descrita pela primeira vez uma superfície estriada intraformacional sobre um diamictito interpretado como subglacial. A superfície foi descoberta pelos estudantes de Mapeamento Sedimentar da Universidade Federal do Paraná em 2016. Consta de um diamictito de aproximadamente $1 \mathrm{~m}$ de espessura de matriz lamítico-arenosa, pobre em clastos, contendo grânulos e um bloco granítico de $1 \mathrm{~m}$ de diâmetro (Fig. 6D). Seu contato basal com xistos pré-cambrianos é encoberto e em seu topo encontra-se superfície estriada intraformacional. A superfície possui $1 \mathrm{~m}^{2}$ e é caracterizada por sulcos rasos e paralelos (Fig. 6E) e por uma possível pequena flute, de aproximadamente $20 \mathrm{~cm}$ de comprimento e $5 \mathrm{~cm}$ de largura contendo um clasto em um de seus extremos. A superfície estriada intraformacional é coberta por 6 metros de folhelhos negros contendo alguns clastos caídos de ocorrência restrita somente na base. A orientação dos sulcos e a cinemática derivada da assimetria da flute indica um sentido de movimento glacial para NW $\left(300^{\circ}\right)$. Esta ocorrência possivelmente estaria incluída na continuação do paleovale de Alfredo Wagner-Vidal Ramos proposto por Fallgatter \& Paim (2019) (Fig. 4B) e o fato de ser recoberta por folhelhos negros como os descritos em Vidal Ramos sugere que pode estar inserida nesta mesma calha glacial.

Em síntese, a discordância basal do Grupo Itararé em Santa Catarina é reconhecida por quase todo o cinturão de afloramento, desde Alfredo Wagner até São Bento do Sul (Fig. 4B). A morfologia da discordância é bastante irregular, apresentando várias formas alongadas moldadas no substrato e depressões locais de poucos metros de profundidade até calhas (troughs) glaciais de maiores dimensões (Figs. 6A, B e C). A orientação de todas as estruturas erosivas glaciais é para NW (variando de $300^{\circ}$ a $357^{\circ}$ ), indicando uma consistência na direção de fluxo das geleiras. Esta superfície glacial evidencia geleiras de base úmida e irregular onde em 
algumas porções fluxos de mais rápida velocidade foram canalizados gerando calhas glaciais. Estas regiões de glacial areal scouring contêm uma alternância de formas alongadas moldadas no substrato e pequenas depressões/bacias que em geral contém uma amplitude menor de 100 m (Benn \& Evans 2010). A posição de pontos altos e baixos em um terreno erodido por massas de gelo reflete variações da litologia do substrato e a densidade e orientação de descontinuidades. Os estratos do Grupo Itararé sobre a discordância basal em Santa Catarina foram depositados em ambiente marinho relativamente profundo, dado que predominam folhelhos negros, sucessões turbidíticas e depósitos de transporte de massa gerados por deslizamentos submarinos. Isto é sugestivo que as geleiras fluindo para NW adentraram o ambiente marinho durante episódios de máximo avanço glacial, que foram seguidos por eventos transgressivos durante deglaciação (e.g. Santos et al. 1996).

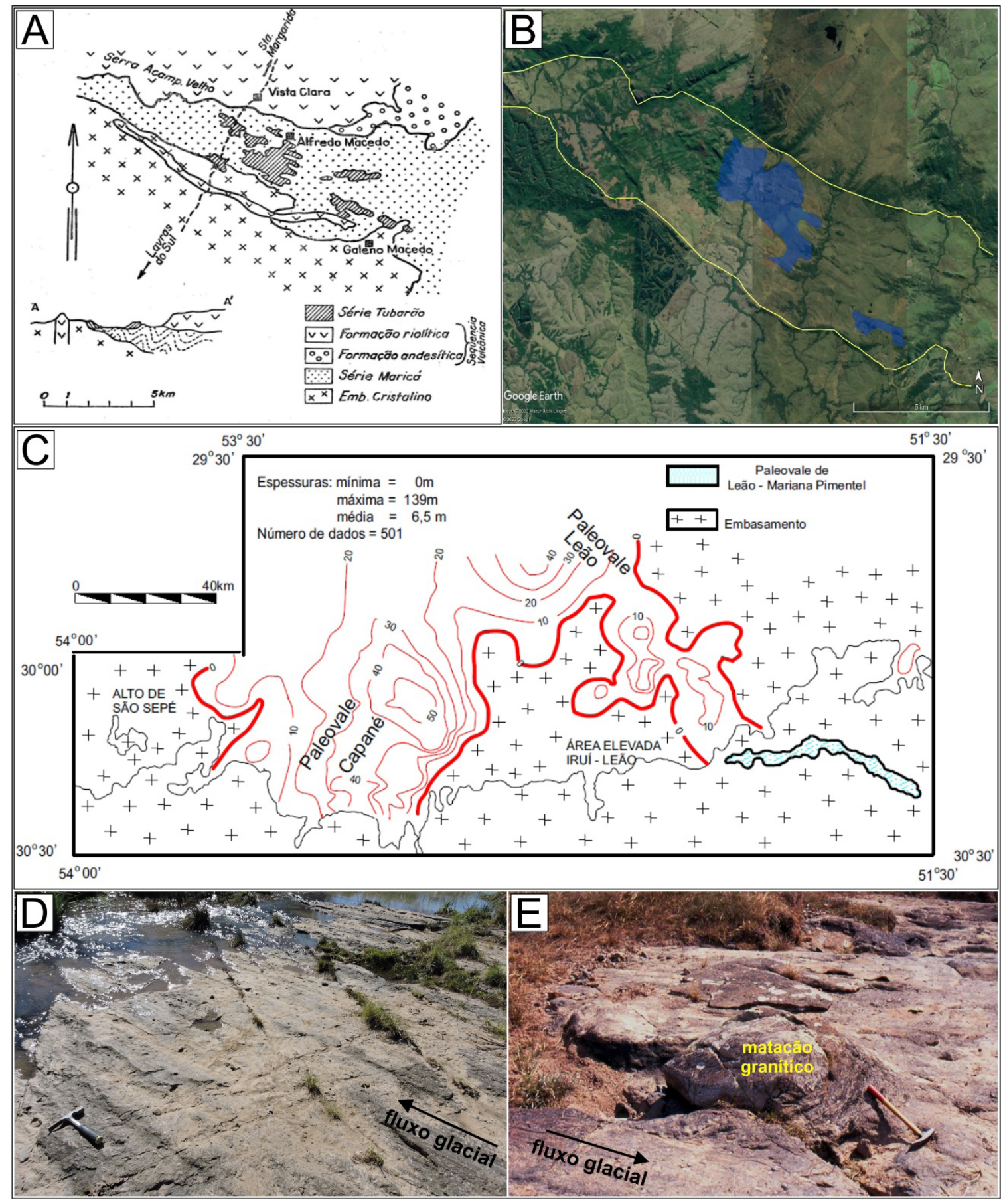

Figura 7 - Feições de erosão glacial no Rio Grande do Sul. A) Esquema original de Mau (1960) para o paleovale Lavras do Sul. B) Imagem do GoogleEarth do paleovale Lavras do Sul contendo estratos do Grupo Itararé (em azul). C) Mapa de isópacas do Grupo Itararé e delineamento dos paleovales Capané, Leão e Marina Pimentel (Lopes 1995). D) Superfície estriada intraformacional de Cachoeira do Sul originalmente descrita por Tomazelli \& Soliani (1982) contendo E) matacão granítico com sedimento deformado à jusante. 


\subsection{Rio Grande do Sul: paleovales glaciais}

No Rio Grande do Sul, a principal feição descrita na discordância basal do Grupo Itararé, que se dá por vezes sobre terrenos ígneos e metamórficos, bem como estratos subhorizontais da Bacia do Camaquã, são paleovales preenchidos por sedimentos glaciais e pós-glaciais (Holz 1999, 2003) (Fig. 4C). Na região de São Gabriel e Lavras do Sul, Mau (1960) documentou dois paleovales glaciais. Somente o paleovale Lavras do Sul conta com uma descrição, onde pequenos morros testemunhos de 6-8 $\mathrm{m}$ de espessura de estratos do Grupo Itararé ocorrem sobre rochas dobradas da Bacia do Camaquã. Estes testemunhos ocorrem dentro de uma depressão entalhada sobre o contato entre rochas vulcânicas da Bacia do Camaquã e granitos do embasamento (Figs. 7A e B). A depressão possui cerca de $18 \mathrm{~km}$ de comprimento e $4 \mathrm{~km}$ de largura e é orientada segundo a direção NW-SE $\left(290^{\circ}\right)$. Os estratos Grupo Itararé são interpretados como preenchimento deste vale, que teria sido entalhado por uma geleira fluindo para noroeste. $\mathrm{O}$ recente mapeamento da carta Lavras do Sul 1:100.000 pela CPRM (Cruz \& Horn 2020) traz em mais detalhe a distribuição dos estratos do Grupo Itararé nesta região.

$\mathrm{Na}$ região de Ibaré, foi mencionado que estratos do Grupo Itararé ocorrem em um paleovale glacial estreito e alongado de $55 \mathrm{~km}$ de comprimento por $2 \mathrm{~km}$ de largura e orientado segundo NW-SE (Mau 1960). Estes depósitos foram estudados posteriormente por Tomazelli \& Soliani (1997) e Fedorchuk et al. (2019a). Estes autores não confirmaram a veracidade de um vale glacial, dado que a ocorrência alongada dos estratos se dá sobre o Lineamento Ibaré, uma zona de cisalhamento NW-SE que separa dois terrenos precambrianos do escudo riograndense. Para Tomazelli \& Soliani (1997), os estratos glaciais foram protegidos de erosão dentro desta depressão estrutural. Nos afloramentos acerca de Ibaré, uma superfície estriada intraformacional orientada N-S foi descrita sobre diamictitos intercalados a ritmitos (Tomazelli \& Soliani 1997). A confirmação desta superfície como sendo gerada na zona subglacial ou por arrasto de quilhas de icebergs ainda está pendente. Os depósitos do Grupo Itararé na região consistem em tilitos subglaciais e leques de deglaciação subaquosos gerados em ambiente terrestre a transicional estuarino. Ademais, Fedorchuk et al. (2019a) descreveram em detalhe deformações glácio-tectônicas em um complexo de morenas de empurrão gerados por oscilações na margem da geleira. A cinemática glacial obtida através das estruturas glácio-tectônicas suporta uma interpretação de fluxo glacial para NW $\left(301^{\circ}\right)$ paralelo ao Lineamento de Ibaré. Consequentemente, os autores levantaram a possibilidade de canalização de uma geleira fluindo para NW, aproveitando-se desta zona de fraqueza pré-existente (Fig. 4C).

Na região de Candiota, há menções sobre um paleofiorde inferido através de análise de isópacas e contendo até $60 \mathrm{~m}$ de depósitos glaciais. O paleofiorde é estreito e alongado segundo a direção NNE-SSW (Fig. 4C). Dias (1993) supôs que a geleira que entalhou o vale fluiu para NNE, enquanto Holz (1999) discutiu que o paleovale foi erodido por geleiras fluindo para SSW, dado o alargamento do vale para o sul e por transgressões marinhas pós-glaciais provindas de sul. Aproximadamente $35 \mathrm{~km}$ a norte de Candiota, uma superfície estriada intraformacional contendo sulcos e flutes foi documentada sobre um diamictito (Tomazelli \& Soliani 1982). A superfície ocorre descontinuamente ao longo de uma meseta plana sustentada pelo diamictito sobre estratos horizontais da Bacia do Camaquã. O paleofluxo glacial foi estimado para NE $\left(15^{\circ}\right)$ devido à assimetria das flutes.

No segmento da região de afloramentos leste-oeste, no centro do estado, em uma área que abrange Caçapava do Sul a Mariana Pimentel, paleovales glaciais também são reconhecidos. Lopes (1995) definiu, a partir de dados de subsuperfície, os paleovales Capané e Leão (Fig. 7C). Segundo o autor, os estratos do Grupo Itararé ocorrem somente confinados nessas depressões. Já as sucessões pós-glaciais ocorrem recobrindo os vales preenchidos pelos estratos do Grupo Itararé, bem como sobre os paleoaltos topográficos adjacentes. O paleovale Capané possui uma forma em $\mathrm{U}$ e aproximadamente $50 \mathrm{~km}$ de largura, enquanto o paleovale Leão apresenta aproximadamente $20 \mathrm{~km}$ de largura. Estratos do Grupo Itararé nestes vales não ultrapassam os $50 \mathrm{~m}$ de espessura. Os vales possuem orientação para NNW e NE e convergem em direção ao centro da bacia. Dias (1993) interpretou o paleovale Leão como sendo um fiorde devido a estratos do Grupo Itararé estarem confinados entre os altos do embasamento.

O Grupo Itararé aflora na extremidade sul do paleovale Capané. Nesta região, uma superfície estriada intraformacional ocorre sobre um diamictito maciço e heterogêneo contendo clastos estriados, facetados e angulosos que resta sobre brechas da Bacia do Camaquã (Tomazelli \& Soliani 1982). A superfície contém sulcos e flutes de vários metros de comprimento (Figura 7D). O fluxo glacial para norte foi inferido através de um matacão granítico de $1 \mathrm{~m}$ de diâmetro que deforma o sedimento à jusante (Fig. 7E).

O paleovale Leão, inferido somente através de testemunhos de sondagem, estende-se a Leste em direção a uma depressão entalhada no embasamento precambriano, alongada segundo a direção NW-SE e preenchida por estratos do Grupo Itararé e da Formação Rio Bonito (pós-glacial), denominado paleovale Mariana Pimentel (Fig. 7C). Este paleovale se estende por $60 \mathrm{~km}$, com uma largura média de $2,5 \mathrm{~km}$, tem uma forma em $\mathrm{U}$ e é interpretado como tendo sido erodido por uma geleira de vale fluindo em direção ao mar, sendo portanto um fiorde (Tedesco et al. 2016). Entretanto, uma interpretação alternativa para a gênese dos paleovales Leão e Mariana Pimentel foi proposta por Fedorchuk et al. (2019b). Os autores contestaram uma origem glacial afirmando que evidências concretas de glaciação não foram observadas. A origem tectônica foi sugerida para estes vales e seus preenchimentos a partir de reativações de falhas do embasamento durante o Permocarbonífero.

É notável o alinhamento dos paleovales descritos no Rio Grande do Sul com zonas de cisalhamento do embasamento (Fig. 4C), tanto os vales profundos e estreitos (fiordes) como os vales amplos e rasos. Reativações de falhas do embasamento e criação de depocentros locais na Bacia do Paraná durante a deposição do Grupo Itara- 
ré são demonstrados (Canuto 1993). Santos et al. (1996) afirmaram que os vales do Rio Grande do Sul são claramente controlados por zonas de cisalhamento do embasamento, provavelmente aprofundadas pelas geleiras. Como sugerido por Fedorchuk et al. (2019b), a gênese dos paleovales pode estar relacionada à criação de depocentros devido a reativações de falhas do embasamento. Ainda, como sugerido por Tomazelli \& Soliani (1997) para o paleovale Ibaré, a preservação destes estratos em depressões pode ter sido condicionada pela tectônica pós-deposicional.

Para a glaciação neopaleozoica no Rio Grande do Sul alguns cenários são possíveis de acordo com o discutido em trabalhos prévios: a) pré-existência de zonas de fraqueza no embasamento, facilitando assim erosão mais efetiva e linear nestas zonas e canalização de geleiras como corredores de gelo e geleiras de vale; b) reativação de falhas do embasamento durante a sedimentação do Grupo Itararé e da Formação Rio Bonito (pós-glacial), condicionando assim depocentros e áreas fonte; e c) deposição dos estratos do Grupo Itararé sem confinamento e com ampla distribuição areal e preservação dos estratos situados em blocos baixos devido à reativação de estruturas do embasamento após a deposição. Embora a questão do controle tectônico versus glacial na criação destes paleovales ainda necessite de mais estudos, no Rio Grande do Sul geleiras avançaram para N, NE e NW, possivelmente encaixadas em vales, influenciando a sedimentação em ambientes glaciais terrestres, estuarinos e marinhos rasos.

\subsection{Marcas de arrasto de quilhas de icebergs: interpretações equivocadas de erosão por geleiras}

Nem todas as superfícies estriadas e sulcadas encontradas no registro geológico foram geradas na base de geleiras. Superfícies estriadas geradas em substrato rochoso são altamente confiáveis que foram produzidas por abrasão subglacial devido às altas pressões basais exercidas no contato entre a geleira e o substrato (Bennett \& Glasser 2009). Em contrapartida, superfícies estriadas e sulcadas desenvolvidas em sedimentos inconsolidados ou semi-consolidados possuem vários modos de formação, tais como: 1) por geleiras, na interface entre a base da geleira e a camada basal deformante, gerando superfícies estriadas intraformacionais (e.g. van der Meer 1997); 2) quando quilhas de icebergs ou gelo flutuante em movimento tocam e arrastam-se sobre o sedimento de fundo (e.g. Woodworth-Lynas \& Dowdeswell 1994, Eyles et al. 2005); e 3) por cisalhamento intraestratal resultante de deslizamentos, escorregamentos e fluxos de detritos subaquosos (e.g. Peakall et al. 2020, Rodrigues et al. 2020).

Ambos os processos são ordinários no ambiente de sedimentação glácio-marinho, porém somente superfícies estriadas geradas subglacialmente podem ser utilizadas para inferir a cinemática e a influência direta de geleiras. A interpretação equivocada de uma superfície estriada em sedimento inconsolidado como sendo glaciogênica pode implicar em interpretações errôneas sobre a direção de movimento de geleiras e de suas áreas-fonte, resultando assim na reconstrução de modelos paleogeográficos incorretos (Rosa 2015).

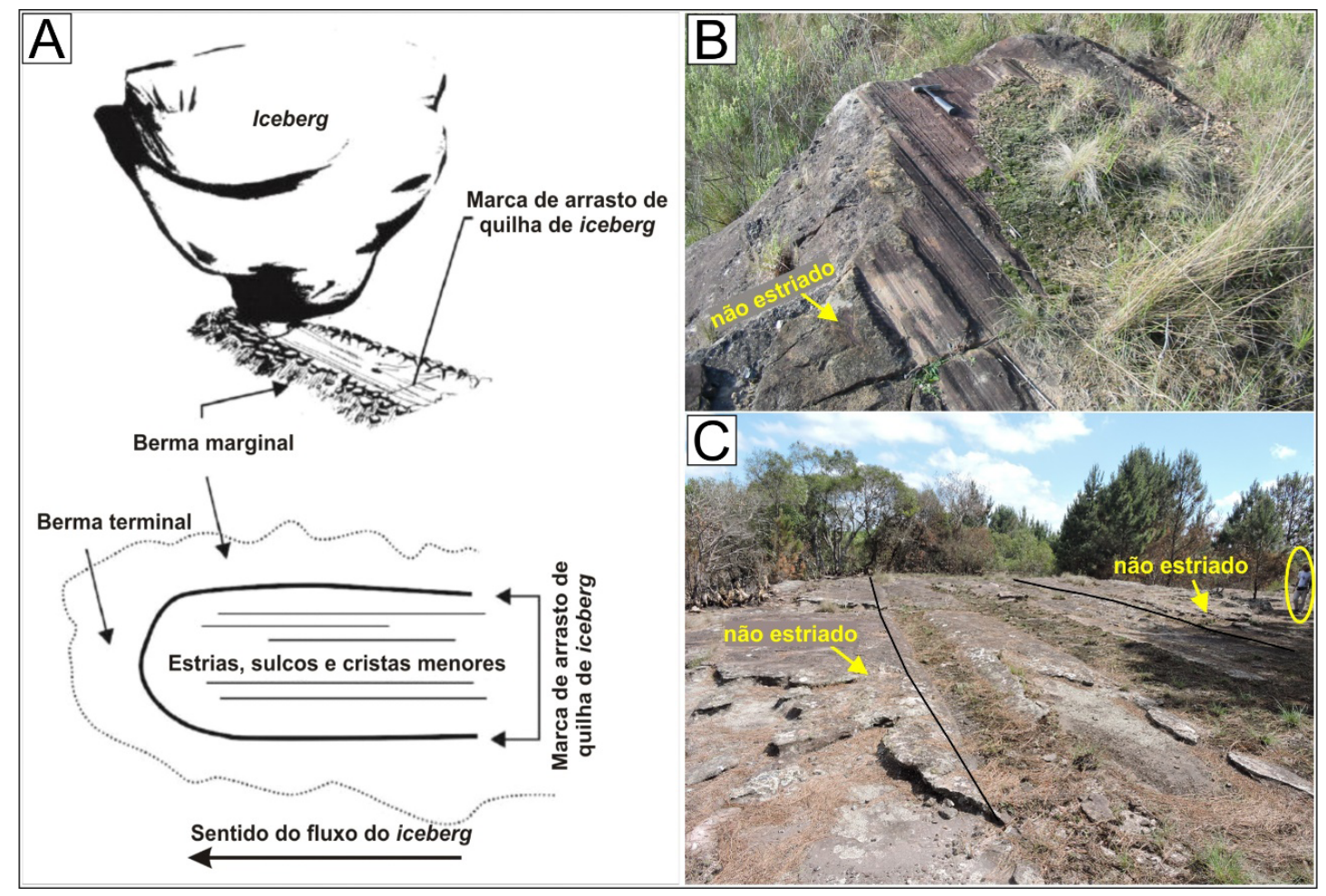

Figura 8-A) Mecanismo de geração de marcas de arrasto de quilhas de icebergs sobre sedimento inconsolidado. Modificado de Vesely \& Assine (2014). B) Marca de arrasto de quilha de iceberg de continuidade lateral limitada sobre arenitos em Lapa (Vesely \& Assine 2014). C) Marca de arrasto de quilha de iceberg de 80 x $5 \mathrm{~m}$ contendo internamente dois sulcos largos desenvolvida sobre arenitos ao longo do Rio das Mortes em Balsa Nova. 
Icebergs são gerados na margem das geleiras e, uma vez desprendidos, são movidos pelo vento, ondas e correntes. Quando quilhas de icebergs são aterradas e tocam o sedimento de fundo, a quilha acaba remodelando o sedimento na medida em que o iceberg se movimenta (Figura 8A). A movimentação de icebergs aterrados então produz sulcos retilíneos a curvilíneos de variáveis larguras (centímetros até centenas de metros), profundidades de centímetros até $25 \mathrm{~m}$ e seus comprimentos podem atingir até dezenas de quilômetros (Woodworth-Lynas \& Dowdeswell 1994). Estes sulcos internamente contêm estrias e sulcos menores e são denominados de marcas de arrasto de quilhas de iceberg (iceberg-keel scour marks).

A distinção de superfícies sulcadas e estriadas geradas por quilhas de icebergs ou na base da geleira deve ser cautelosa e alguns critérios são utilizados nesta distinção (Woodworth-Lynas \& Dowdeswell 1994). Quilhas de iceberg geralmente não possuem grande continuidade lateral, os sulcos gerados têm uma largura restrita, diferentemente de geleiras que possuem grande continuidade lateral e geram superfícies estriadas de maior extensão areal. O mecanismo de geração de flutes é restrito à zona subglacial devido à passagem de gelo sobre obstáculos como clastos. Ademais, ao remodelar o substrato, quilhas de icebergs possuem um mecanismo similar ao de um arado, onde o sedimento remodelado é movimentado nas adjacências do sulco. Este processo gera cristas ou bermas marginais que de maneira paralela bordejam os sulcos. Sedimentos de cristas ou bermas podem escorregar para dentro dos sulcos gerando pequenos lobos de escorregamento.

Além destes critérios morfológicos, a interpretação da gênese das camadas sob e sobrepostas aos sulcos é de suma importância na definição do mecanismo que gerou a superfície estriada. Geleiras tendem a deformar o substrato inconsolidado, gerando rochas homogeneizadas e maciças (diamictitos subglaciais) ou sucessões intensamente dobradas e cisalhadas. Em contrapartida, sulcos produzidos por icebergs são comumente encontrados em camadas que não estão associadas diretamente à ação do gelo.

Embora pareça um processo incomum, marcas de arrasto de quilha de iceberg são mais comuns no registro geológico do que previamente estimado (Woodworth-Lynas \& Dowdeswell 1994, Vesely \& Assine 2014, Rosa 2015). No sul do Brasil, estas feições ocorrem em abundância no sudeste do Paraná (Balsa Nova e Palmeira) bem como algumas ocorrências são descritas em Santa Catarina (Fig. 4).

Nas pedreiras de Trombudo Central, em Santa Catarina, Santos et al. (1992) descreveram e interpretaram as primeiras marcas de arrasto de quilhas de iceberg da Bacia no Paraná, bem como do registro estratigráfico de glaciações pré-cenozoicas. As feições consistem em sulcos longos, sinuosos e subparalelos sobre planos de estratificação de ritmitos. As bermas marginais e a base dos sulcos contêm pequenas falhas reversas e dobras que indicam deformação local do substrato inconsolidado a semi-consolidado devido à movimentação do iceberg.

Na região que abrange Lapa, Vila Velha, Palmeira e Balsa Nova no Paraná, várias superfícies estriadas foram descritas e interpretadas como produtos do arrasto de quilhas de icebergs ou devido à erosão subglacial (Fig. 4A). Durante o mapeamento da borda da Bacia do Paraná pela Comissão da Carta Geológica do Paraná, Bigarella et al. (1967) descreveram aproximadamente 20 superfícies estriadas. Estas superfícies estão tanto sobre arenitos devonianos da Formação Furnas como em arenitos do Grupo Itararé. Os autores atribuíram todas estas superfícies à abrasão subglacial, embora tenham sido desenvolvidas em diferentes contextos: sobre substrato rígido da Formação Furnas e sobre sedimentos inconsolidados do Grupo Itararé.

Dentre as superfícies estriadas descritas por Bigarella et al. (1967), quatro superfícies estriadas em uma sucessão de arenitos do Grupo Itararé de aproximadamente 10 $\mathrm{m}$ de espessura no vale do Rio do Salto, Palmeira, foram reinterpretadas (Vesely \& Assine 2002, 2014, Trosdtorf et al. 2005b). As superfícies estriadas estão sobre camadas de arenitos, são lateralmente descontínuas e com perfil transversal côncavo, em alguns casos com bermas marginais. Vesely \& Assine (2002) interpretaram a gênese destas superfícies a partir de quilhas de plataformas de gelo, porém levantaram a possibilidade de terem sido formadas por quilhas de iceberg. Já Trosdtorf et al. (2005b) interpretaram estas superfícies como geradas na zona subglacial por flutuações sazonais da margem de uma geleira marinha de base aterrada.

Vesely \& Assine (2014) demostraram para várias superfícies nas regiões de Lapa, Vila Velha, Palmeira e São Luiz do Purunã, incluindo as superfícies do vale do Rio do Salto, uma origem por arrasto de quilhas de icebergs (Fig. 8B). Os autores mostraram como estas superfícies são mais comuns no registro estratigráfico do que previamente considerado. Ademais, discutiram como a direção destas estrias geradas por icebergs impactam nos modelos paleogeográficos de glaciação na Bacia do Paraná e no Gondwana, já que a cinemática inferida a partir delas não é a cinemática de geleiras. Ainda na região de Balsa Nova, várias outras marcas de arrasto de quilhas de iceberg foram recentemente descritas sobre arenitos do Grupo Itararé, algumas podendo chegar até $80 \mathrm{~m}$ de comprimento por $5 \mathrm{~m}$ de largura (Rosa et al. 2019) (Fig. 8C).

\section{4. Áreas-fonte das massas de gelo}

Os centros glaciais que nuclearam as geleiras que adentraram a Bacia do Paraná durante a LPIA foram inferidos a partir de estudos de: 1) paleocorrentes em sequências de deglaciação glácio-marinhas (e.g. Aquino et al. 2016, Carvalho \& Vesely 2017, Mottin et al. 2018, Fallgatter \& Paim 2019); 2) composição e orientação de clastos em diamictitos (e.g. Martin 1961, Bigarella et al. 1967); 3) isólitas de diamictito em subsuperfície (e.g. França \& Potter 1988); 4) orientação de estruturas erosivas glaciogênicas e glácio-tectônicas (e.g. Santos et al. 1996, Fedorchuk et al. 2019a, Rosa et al. 2016, 2019); e mais recentemente, 5) anisotropia de susceptibilidade magnética (e.g. Amato 2017, Raposo et al. 2021); 6) geocronologia $\mathrm{U} / \mathrm{Pb}$ em zircão detrítico (e.g. Canile et al. 2016, Griffis et al. 2019a, Tedesco et al. 2019). Consequentemente, várias hipóteses com respeito à cinemática glacial e áreas-fonte foram propostas (Fig. 9). 


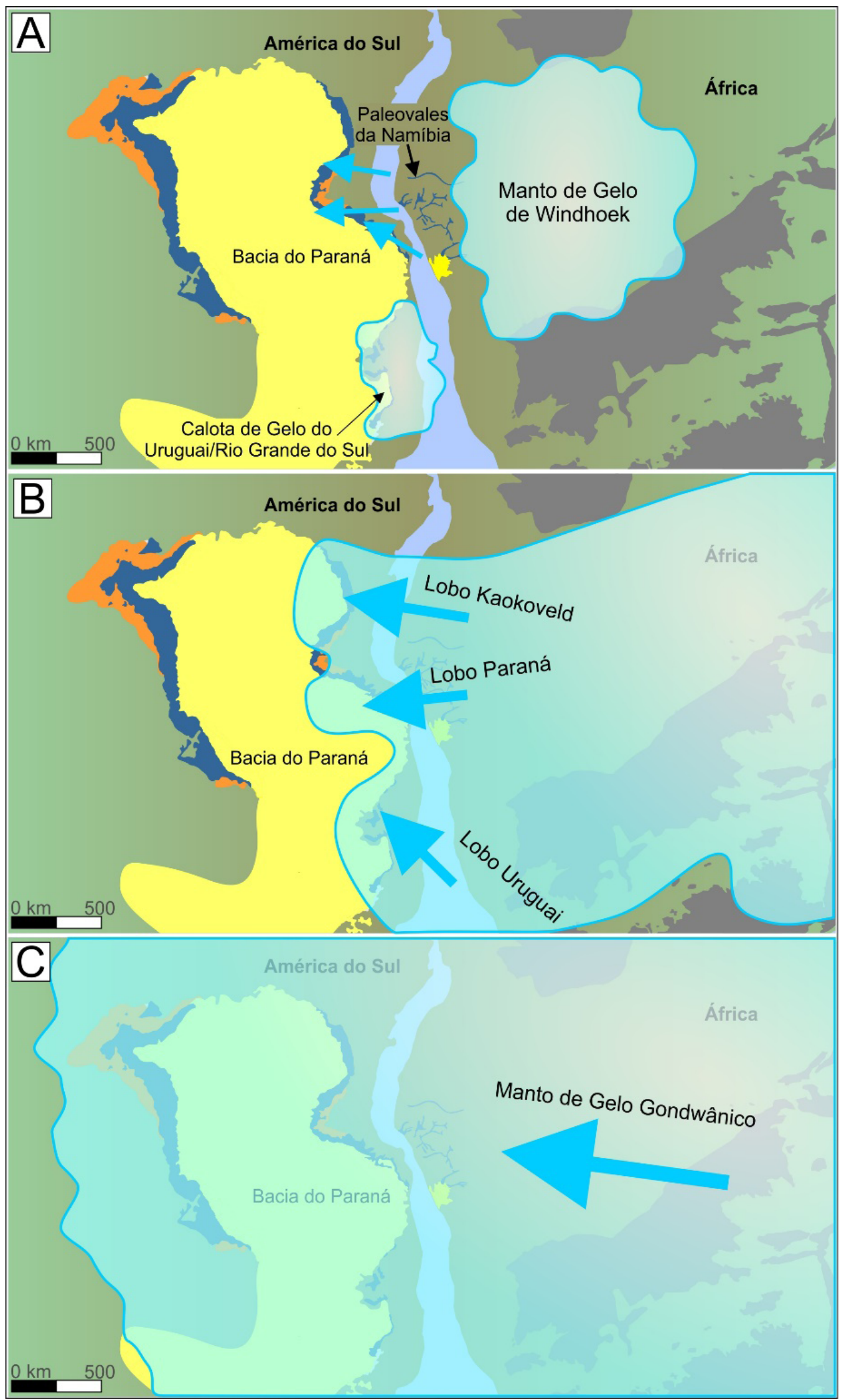

Figura 9 - Modelos paleogeográficos de áreas-fonte para as geleiras neopaleozoicas nas bordas leste e sul da Bacia do Paraná: A) Calota e manto de gelo individuais nas adjacências da bacia emanando geleiras até as margens da bacia (e.g. Santos et al. 1996, Rocha-Campos et al. 2008). B) Lobos glaciais provindos de um mesmo manto de gelo que adentraram porções da bacia (e.g. Frakes \& Crowell 1969, Crowell \& Frakes 1975). C) Imenso manto de gelo centrado na Antártica que cobriu toda a bacia (e.g. Gesicki et al. 2002). 
Desde a inferência do Manto de Gelo Gondwânico por Du Toit (1937), há consenso entre as várias gerações que desenvolveram pesquisas no Grupo Itararé de que as massas de gelo da borda leste da Bacia do Paraná vieram da África. Isto se deve à presença de paleovales glaciais incisos sobre terrenos precambrianos no noroeste da Namíbia e que foram escavados por geleiras fluindo para o oeste (Martin 1953,1961,1981). Este paleofluxo glacial é paralelo ao fluxo glacial predominante para NW das geleiras na borda leste da Bacia do Paraná quando os continentes Africano e Sul-americano encontravam-se justapostos. Entretanto, não há consenso sobre o quanto estas geleiras adentraram na Bacia do Paraná.

Crowell \& Frakes (1975) realizaram a primeira reconstrução paleogeográfica da glaciação nos continentes que uma vez compunham o Gondwana. Os autores inferiram o Lobo Kaokoveld e o Lobo Paraná provindos de um manto de gelo centrado no leste da África. Esses lobos teriam influenciado a deposição na borda leste da Bacia do Paraná, desde São Paulo até Santa Catarina (Fig. 9B). Santos et al. (1996) sugeriram a distinção do Manto de Gelo de Windhoek, situado na região das terras elevadas de Windhoek, na Namíbia, como sendo o responsável por emanar os lobos Kaokoveld, Paraná e Rio do Sul até a borda leste da Bacia do Paraná (Fig. 9A). O Lobo Rio do Sul foi definido como tendo até $200 \mathrm{~km}$ de comprimento e $100 \mathrm{~km}$ de largura (Canuto 1993) e adentrou a bacia posteriormente aos lobos Kaokoveld e Paraná, os quais já estavam ativos. Estes lobos glaciais foram interpretados como terminações lobadas de corredores de gelo que fluíram de altos topográficos na Namíbia até o nível do mar e adentraram aterrados até aproximadamente $200 \mathrm{~km}$ no "mar Itararé", onde teriam se expandido formando lobos glaciais.

Detalhamento na borda leste da Bacia do Paraná sugere que o Lobo Paraná pode ser subdivido em dois lobos individualizados - Lobo Paraná Sul e Lobo Paraná Norte (Vesely et al. 2015, Rosa et al. 2019). Estes lobos glaciais foram interpretados como não confinados pela topografia, dado que a superfície erosiva glacial é plana e lateralmente contínua. Ainda, a história glacial de recuo e avanço destes lobos foi reconstruída devido a diferentes direções de fluxo glacial documentadas no estado do Paraná (N, SW e NW), representando os primeiros episódios de glaciação na Bacia do Paraná durante o Mississippiano.

Fallgatter \& Paim (2019) sugeriram, após definirem o vale glacial que se entende desde a região de Alfredo Wagner até Vidal Ramos, que corredores de gelo devem ter sido o principal tipo de geleiras que adentraram a Bacia do Paraná. No estado de Santa Catarina, o fluxo glacial é constante para NW e a superfície gerada pelas geleiras é bastante irregular a qual se sobrepõem estratos marinhos profundos, indicando que estes corredores se estenderam até o ambiente marinho.

Numa visão distinta a do modelo mais aceito para a glaciação na borda leste da Bacia do Paraná, o qual vem sendo constantemente refinado, Gesicki et al. (2002) propuseram que o Manto de Gelo Gondwânico centrado no sul da África/Antarctica teria fluido para NW cobrindo assim toda a extensão da Bacia do Paraná e grande parte do Gondwana (Fig. 9C). Esta hipótese foi baseada na descoberta de superfícies estriadas na Formação Aquidauana na borda oeste da bacia que indicam paleofluxo glacial para NW, paralelo ao fluxo geral da borda leste. Entretanto, Rosa et al. (2016) sugeriram que pelo menos parte destas superfícies podem ser marcas de arrasto de quilhas de icebergs e que, por consequência, não seriam indicadores do avanço de geleiras. Apesar de algumas divergências, a maioria dos autores defende a hipótese de centros glaciais de menor extensão e localizados nas adjacências da bacia (e.g. Santos et al. 1996, Fielding et al. 2008, Isbell et al. 2012, Vesely et al. 2015, Rosa et al. 2016, Fallgatter \& Paim 2019).

No Rio Grande do Sul não há consenso sobre a área fonte de geleiras que transportaram sedimentos até a borda sul da Bacia do Paraná. Enquanto uma visão sugere uma pequena calota de gelo local sobre o escudo riograndense ou no Uruguai (e.g., Santos et al. 1996, Rocha-Campos et al. 2008, Tedesco et al. 2019), outra visão de pensamento interpreta geleiras nesta região provindas de um centro glacial parcialmente situado na África (e.g., Frakes \& Crowell 1969, Fedorchuk et al. 2021).

Os modelos pioneiros sugeriram que o Lobo Uruguai, provindo do mesmo manto de gelo que continha os lobos Kaokoveld e Paraná, avançou do sul da África para norte sobre o Uruguai e o Rio Grande do Sul (Frakes \& Crowell 1969, Crowell \& Frakes 1975, Crowell 1999) (Fig. 9B). De acordo com estes trabalhos, estes três lobos glaciais coalesceram no interior da Bacia do Paraná durante o máximo avanço glacial. Em contrapartida, a orientação dos paleovales juntamente com as superfícies estriadas intraformacionais no Rio Grande do Sul sugerem um aspecto radial de fluxo glacial, motivo este que levou à interpretação de uma calota de gelo local situada sobre o escudo riograndense (Fig. 9A). Esta região foi interpretada como um terreno topograficamente elevado que emanou geleiras radialmente fluindo bacia adentro (Santos et al. 1996, Holz 1999, Rocha-Campos et al. 2008).

Esta discussão envolvendo uma calota de gelo local sobre o escudo riograndense e Uruguai ou a proveniência de geleiras no sul da África foi retomada recentemente através de dados de geocronologia $\mathrm{U} / \mathrm{Pb}$ em zircão detrítico do Grupo Itararé e da equivalente Formação San Gregorio no Uruguai (Griffis et al. 2019a, Tedesco et al. 2019, Fedorchuk et al. 2021). Diferentes populações de zircão analisadas levaram à interpretação de um centro glacial local isolado sobre o sul do Brasil e Uruguai ou geleiras provindas de um manto de gelo no sul da África. A discussão continua em aberto.

\section{Considerações finais}

Embora ainda não se disponha de um modelo integral detalhado da LPIA na Bacia do Paraná, resultados locais obtidos nas últimas décadas estão detalhando cada vez mais os complexos eventos ocorridos nesta época. A exploração de sucessões previamente não conhecidas e a reinterpretação de localidades em termos de conhecimentos sedimentológicos e estratigráficos modernos 
estão contribuindo muito na definição de ciclos de avanço e recuo de geleiras e na individualização de diferentes massas de gelo atuantes durante a era glacial. Em especial no Sul do Brasil, é visto que o registro de erosão e deposição glacial difere entre regiões, possivelmente relacionado aos diferentes episódios de glaciação e/ou a natureza do substrato sobre o qual as geleiras se deslocaram. No Paraná, o registro glacial permite inferir geleiras não confinadas e de base plana, enquanto em Santa Catarina o avanço de geleiras sobre terrenos ígneos e metamórficos gerou uma topografia muito irregular que sugere a presença de corredores de gelo. Já no escudo riograndense, paleovales preenchidos por estratos glaciais e pós-glaciais são interpretados como produto ou da ação glacial e/ou tectonismo.

Alguns pontos sobre a evolução de conceitos que podem ser ressaltados neste trabalho incluem a transição de uma interpretação de geleiras terrestres que dominava no século passado para a interpretação de geleiras marinhas bem como suas morfologias. Vale destacar também o conhecimento sobre diferentes episódios de glaciação em diferentes regiões da bacia, assim como a distinção da gênese de feições erosivas ordinariamente interpretadas como glaciogênicas e agora reinterpretadas como geradas por outros agentes. Por fim, a reinterpretação de diamictitos, anteriormente interpretados como glaciogênicos, como produtos de fluxos gravitacionais subaquáticos é um avanço importante.
Um dos maiores problemas no detalhamento da história glacial na Bacia do Paraná é a falta de controle cronológico, dado que datações radiométricas são raras nos estratos do Grupo Itararé e as palinozonas possuem ampla abrangência temporal. Isto dificulta a correlação detalhada de estratos e consequentemente a definição da duração de ciclos de avanço e recuo das massas de gelo, bem como reconstruções paleogeográficas. Progresso nesses quesitos tem sido alcançado, principalmente para a porção superior do Grupo Itararé e para os estratos pós-glaciais da Formação Rio Bonito, onde novas idades radiométricas e calibração das palinozonas estão restringindo melhor os últimos episódios de glaciação na Bacia do Paraná (Cagliari et al. 2016, Griffis et al. 2019b, Valdez et al. 2019, Souza et al. 2021, Mottin et al. 2021 neste volume). Já para os estratos mais antigos do Grupo Itararé, datações radiométricas e palinológicas ainda são necessárias para melhor compreender os primeiros episódios de glaciação.

\section{Agradecimentos}

Esta contribuição é parcialmente resultado de pesquisas de campo realizadas durante 2015 a 2019 com apoio financeiro da CAPES, CNPq (461650/2014-2, PQ 302842/2017-9) e NSF (OISE-1444181, OISE-1559231, EAR-1729219). Os autores agradecem à Universidade Federal do Paraná (UFPR) e o Laboratório de Análise de Bacias (LABAP) pelo apoio e infraestrutura e aos colegas que colaboraram como assistentes em trabalhos de campo.

\section{Referências}

AMATO J.A. 2017. Using AMS to help interpret glaciogenic deposits of the Late Paleozoic Ice Age in the Paraná Basin, Brazil. Dissertação de Mestrado, Departamento de Geociências, University of Wisconsin-Milwaukee, 146p.

AQUINO C.D., BUSO V.V., FACCINI U.F., MILANA J.P., PAIM P.S.G. 2016. Facies and depositional architecture according to a jet efflux model of a late Paleozoic tidewater grounding-line system from the Itararé Group (Paraná Basin), southern Brazil. Journal of South American Earth Sciences, 67:180-200.

ASSINE M.L., VESELY F.F. 2008. Ambientes Glaciais. In: SILVA A.J.C.L., ARAGÃO M.A.N.F., MAGALHÃES A.J.C. (eds) Ambientes de Sedimentação Siliciclástica do Brasil. Beca-BALL Edições, São Paulo, 25-51p.

BARBOSA O. 1940. Estrias produzidas por gelo permocarbonifero. Mineração e Metalurgia, 4:272-273.

BENN D.I., EVANS D.J.A. 2010. Glaciers and Glaciation. Hodder Education, London, 817p.

BENNET M., GLASSER N. 2009. Glacial geology: ice sheets and landforms. Wiley-Blackwell, Oxford, 385p.

BIGARELLA J.J., SALAMUNI R., FUCK R.A. 1967. Striated surfaces and related features, developed by the Gondwana ice sheets (state of Parana, Brazil). Palaeogeography, Palaeoclimatology, Palaeoecology, $3: 265-276$
BOULTON G.S., DEYNOUX M. 1981. Sedimentation in glacial environments and the identification of tills and tillites in ancient sedimentary sequences. Precambrian Research, 15:397-422.

BOULTON G.S., DOBBIE K.E., ZATSEPIN S. 2001. Sediment deformation beneath glaciers and its coupling to the subglacial hydraulic system. Quaternary International, 86:3-28.

CAGLIARI J., PHILIPP R.P., BUSO V.V., NETTO R.G., HILLEBRAND P.K., LOPES R.C., BASEI M.A.S., FACCINI U.F. 2016. Age constraints of the glaciation in the Paraná Basin: evidence from new U-Pb dates. Journal of the Geological Society, 173:871-874.

CANILE F.M., BABINSKI M., ROCHA-CAMPOS A.C. 2016. Evolution of the Carboniferous-Early Cretaceous units of Paraná Basin from provenance studies based on $\mathrm{U}-\mathrm{Pb}$, $\mathrm{Hf}$ and $\mathrm{O}$ isotopes from detrital zircons. Gondwana Research, 40:142-169.

CANUTO J.R. 1993. Fácies e ambientes de sedimentação da Formação Rio do Sul (Permiano), Bacia do Paraná, na região de Rio do Sul, estado de Santa Catarina. Tese de Doutorado, Instituto de Geociências, Universidade de São Paulo, 164p.

CAPUTO M.V., CROWELL J.C. 1985. Migration of glacial centers across Gondwana during Paleozoic Era. GSA Bulletin, 96:1020-1036. 
CAPUTO M.V., MELO J.H.G., STREEL M., ISBELL J.L. 2008. Late Devonian and Early Carboniferous glacial records of South America. In: FIELDING C.R., FRANK T.D, ISBELL J.L. (eds) Resolving the Late Paleozoic Ice Age in Time and Space. GSA Special Paper 441, 161-173p.

CARVALHO B.M.V. 2014. Confined turbidite sand-sheets in the Paraná and Paganzo Basins. Dissertação de Mestrado, Programa de Pós-Graduação em Geologia, Universidade do Vale do Rio do/s Sinos, 92p.

CARVALHO P.F. 1940. Estrias glaciais em granodiorito sobposto ao Gondwana de Santa Catarina. Mineração e Metalurgia, 4:271-272

CARVALHO A.H., VESELY F.F. 2016. Facies relationships recorded in a Late Paleozoic fluviodeltaic system (Paraná Basin, Brazil): Insights into the timing and triggers of subaqueous sediment gravity flows. Sedimentary Geology, 352:45-62.

CRUZ R.F., HORN, B.L.D. 2020. Carta geológica Lavras do Sul SHI.22-Y-A-IV. Porto Alegre, CPRM, Projeto Escudo Sul-Rio-Grandense, mapa geológico, escala 1:100.000.

CROWELL J.C. 1957. Origin of pebbly mudstones. GSA Bulletin 68:993-1010.

CROWELL J.C. 1999. Pre-Mesozoic Ice Ages: Their Bearing on Understanding the Climate System. GSA Memoirs, 192:1-112.

CROWELL J.C., FRAKES L.A. 1975. The Late Paleozoic Glaciation. In: CAMPBELL K.S.W. (ed) Gondwana Geology: Papers presented at the Third Gondwana Symposium. Australian National University Press, Canberra, 313-331p.

DARVILL C.M., STOKES C.R., BENTLEY M.J., EVANS D.J.A., LOVELL H. 2016. Dynamics of former ice lobes of the southernmost Patagonian Ice Sheet based on a glacial landsystems approach. Journal of Quaternary Science, 32(6):857-876.

DERBY O.A. 1878. A geologia da região diamantífera da Província do Paraná. Arquivos do Museu Nacional, 3:89-96.

DIAS M.E.R. 1993. Associações Microflorísticas dos Paleovales do Grupo Itararé no Rio Grande do Sul, Permiano da Bacia do Paraná, Brasil. Pesquisa em Geociências, 20:132-140.

DYKSTRA M., GARYFALOU K., KERTZNUS V., KNELLER B., MILANA J.P., MOLINARO M., SZUMAN M., THOMPSON P. 2011. Masstransport deposits: combining outcrop studies and seismic forward modeling to understand lithofacies distributions, deformation, and their seismic stratigraphic expression. In: SHIPP R.C., WEIMER P., POSAMENTIER H.W. (eds) Mass-transport Deposits in Deepwater Settings. SEPM Special Publication 96, 293-310p.

DU TOIT A.L. 1937. Our Wandering Continents. Oliver and Boyd Ltd., Edinburgh, 366p.
EVANS D.J. 2018. Till: A glacial process sedimentology. Wiley-Blackwell, West Sussex, 390p.

EVANS D.J., PHILLIPS E.R., HIEMSTRA J.F., AUTON C.A. 2006. Subglacial till: Formation, sedimentary characteristics and classification. Earth-Science Reviews, 78:115-176.

EYLES C.H., EYLES N. 2010. Glacial Deposits. In: JAMES N.P., DALRYMPLE R.W. (eds) Facies Models 4. Geological Association of Canada, 73-104p.

EYLES N., EYLES C.H., WOODWORTH-LYNAS C., RANDALL T.A. 2005. The sedimentary record of drifting ice (early Wisconsin Sunnybrook deposit) in an ancestral ice-dammed Lake Ontario, Canada. Quaternary Research, 63:171-181.

FALLGATTER C., PAIM P.S.G. 2019. On the origin of the Itararé Group basal nonconformity and its implications for the Late Paleozoic glaciation in the Paraná Basin, Brazil. Palaeogeography, Palaeoclimatology, Palaeoecology, 531(B), 108225.

FEDORCHUK N.D, ISBELL J.L., GRIFFIS N.P., VESELY F.F., ROSA E.L.M., MONTAÑEZ I.P., MUNDIL R., YIN, Q-Z., IANUZZI R., ROESLER G., PAULS K.N. 2019a. Carboniferous glaciotectonized sediments in the southernmost Paraná Basin, Brazil: Ice marginal dynamics and paleoclimate indicators. Sedimentary Geology, 389:54-72.

FEDORCHUK N.D, ISBELL J.L., GRIFFIS N.P., MONTAÑEZ I.P., VESELY F.F., IANNUZZI R., MUNDIL R., YIN Q-Z., PAULS K., ROSA E.L.M. 2019b. Origin of paleovalleys on the Rio Grande do Sul Shield (Brazil): Implications for the extent of late Paleozoic glaciation in west-central Gondwana. Palaeogeography, Palaeoclimatology, Palaeoecology, 531(B): 108738 .

FEDORCHUK N.D., GRIFFIS N.P., ISBELL J.L., GOSO C., ROSA E.L.M., MONTAÑEZ I.P., YIN Q-Z., HUYSKENS M.H., SANBORN M.E., MUNDIL R., VESELY F.F., IANNUZZI R. 2021. Provenance of late Paleozoica glacial/post-glacial deposits in the eastern Chaco-Paraná Basin, Uruguay and southernmost Paraná Basin, Brazil. Journal of South American Earth Sciences, 106:102989

FIELDING C.R., FRANK T.D., ISBELL J.L. 2008. The late Paleozoic ice age - a review of current understanding and synthesis of global climate patterns. In: FIELDING C.R., FRANK T.D, ISBELL J.L. (eds.). Resolving the Late Paleozoic Ice Age in Time and Space. GSA Special Paper 441, 343-354p.

FRAKES L.A., CROWELL J.C. 1969. Late Paleozoic Glaciation: I, South America. Geological Society of America Bulletin, 80:1007-1042.

FRANÇA A.B., POTTER P.E. 1988. Estratigrafia, ambiente deposicional e análise de reservatório do Grupo Itararé (Permocarbonífero), Bacia do Paraná (parte 1). Boletim de Geociências da Petrobrás, 2:147-191. 
GARCIA A.M., TRZASKOS B., VESELY F., ROSA E.M., ISBELL，J. 2021. Rochas glaciais sob o microscópio: microtexturas e microestruturas em fácies do Grupo Itararé. Boletim Paranaense de Geociências, no prelo.

GESICKI A.L.D., RICCOMINI C., BOGGIANI P.C. 2002. Ice flow during late Paleozoic glaciation in western Parana Basin, Brazil. Journal of South American Earth Sciences, 14:933-939.

GOOGLE EARTH. 2020. Image Maxar Technologies. Google Inc.

GRIFFIS N.P., MONTAÑEZ I.P., FEDORCHUK N.D, ISBELL J.L, MUNDIL R., VESELY F.F, WEINSHULTZ L., IANNUZZI R., GULBRANSON E., TABOADA A., PAGANI A., SANBORN M.E., HUYSKENS M., WIMPENNY J., LINOL B., YIN Q.Z. 2019. Isotopes to ice: Constraining provenance of glacial deposits and ice centers in west-central Gondwana. Palaeogeography, Palaeoclimatology, Palaeoecology, 531(B):108745.

GRIFFIS N.P,, MONTAÑEZ I.P., MUNDIL R., RICHEY J., ISBELL J., FEDORCHUK N., LINOL B., IANNUZZI R., VESELY F., MOTTIN T., ROSA E., KELLER B., YIN Q-Z. 2019b. Coupled stratigraphic and $\mathrm{U}-\mathrm{Pb}$ zircon age constraints on the late Paleozoic icehouse-to-greenhouse turnover in south-central Gondwana. Geology, 47:1146-1150.

HAMBREY M.J., GLASSER N.F. 2012. Discriminating glacier thermal and dynamic regimes in the sedimentary record. Sedimentary Geology, 251252:1:33.

HART J.K. 1995. Subglacial erosion, deposition and deformation associated with deformable beds. Progress in Physical Geography, 19:173-191.

HOLZ M. 1999. Early Permian sequence stratigraphy and the palaeophysiographic evolution of the Paraná Basin in southernmost Brazil. Journal of African Earth Sciences, 29:51-61.

HOLZ M. 2003. Sequence stratigraphy of a lagoonal estuarine system - and example from the lower Permian Rio Bonito Formation, Paraná Basin, Brazil. Sedimentary Geology, 162:305-331.

HOLZ M., FRANÇA A.B., SOUZA P.A., IANUZZI R., ROHN R., 2010. A stratigraphic chart of the late Carboniferous/Permian succession of the eastern border of the Paraná Basin, Brazil, South America. Journal of South American Earth Sciences, 29:381399.

ISBELL J.L., MILLER M.F., WOLFE K.L., LENAKER P.A. 2003. Timing of late Paleozoic Glaciation in Gondwana: Was glaciation responsible for the development of northern hemisphere cyclothems? In: CHAN M.A., ARCHER A.W. (eds) Extreme depositional environments: Mega end members in geologic time. GSA Special Paper 370, 5-24p.
ISBELL J.L., HENRY L.C., GULBRANSON E.L., LIMARINO C.O., FRAISER M.L., KOCH Z.J., CICCIOLI P.L., DINEEN A.A. 2012. Glacial paradoxes during the late Paleozoic ice age: Evaluating the equilibrium line altitude as control on glaciation. Gondwana Research, 22:1-19.

KRABBENDAM M., GLASSER N.F. 2011. Glacial erosion and bedrock properties in NW Scotland: Abrasion and plucking, hardness and joint spacing. Geomorphology, 130:374-383.

LOPES R.C. 1995. Arcabouço aloestratigráfico para o intervalo "Rio Bonito-Palermo" (Eopermiano da Bacia do Paraná), entre Butiá e São Sepé, Rio Grande do Sul. Dissertação de Mestrado, Departamento de Geologia, Universidade do Vale do Rio dos Sinos, 254p.

LÓPEZ-GAMUNDÍ O., LIMARINO C.O., ISBELL J.L., PAULS K., CÉSARI S.N., ALONSOMURUAGA P.J. 2021. The late Paleozoic Ice Age along the southwestern margin of Gondwana: Facies models, age constraints, correlation and sequence stratigraphic framework. Journal of South American Earth Sciences, 107:103056.

MARTIN H. 1953. Notes on the Dwyka Succession and on some Pre-Dwyka Valleys in South West Africa. Transactions of the Geological Society of South Africa, 56:37-41.

MARTIN H. 1961. The hypothesis of continental drift in the light of recent advances of geological knowledge in Brazil and in South West Africa. Alex L. du Toit Memorial Lectures 7, The Geological Society of South Africa, Johannesburg, 47p.

MARTIN H. 1981. The Late Palaeozoic Dwyka Group of the South Kalahari Basin in Namibia and Botswana and the subglacial valleys of the Kaokoveld in Namibia. In: HAMBREY M.J., HARLAND W.B. (eds) Earth's Pre-Pleistocene Glacial Record. Cambridge University Press, Cambridge, 61-66p.

MAU H. 1960. Vale pré-glacial ao norte de Lavras do Sul, R.G.S. Boletim da Sociedade Brasileira de Geologia, 9:79-82.

MONTAÑEZ I.P., POULSEN C.J. 2013. The late Paleozoic ice age: an evolving paradigm. Annual Review of Earth \& Planetary Sciences, 41:1-28.

MOTTN T.E., VESELY F.F. 2021. Formação Taciba: última manifestação glacial no Paraná. Boletim Paranaense de Geociências, no prelo.

MOTTIN T.E., VESELY F.F., RODRIGUES M.C.N.L., KIPPER F., SOUZA P.A. 2018. The paths and timing of late Paleozoic ice revisited: New stratigraphic and paleo-ice flow interpretations from a glacial succession in the upper Itararé Group (Paraná Basin, Brazil). Palaeogeography, Palaeoclimatology, Palaeoecology, 490:488-504. 
PEAKALL J., BEST J., BAAS J.H., HODGSON D.M., CLARE M.A., TALLING P.J., DORRELL R.M., LEE D.R. 2020. An integrated process-based model of flutes and tool marks in deep-water environments: Implications for palaeohydraulics, the Bouma sequence and hybrid event beds, 67(4):1601-1666.

PHILLIPS E. 2018. Glaciotectonics. In: MENZIES J., VAN DER MEER J. (eds) Past Glacial Environments. Elsevier, Amsterdam, 467-502p.

PHILLIPS E., EVEREST J., DIAZ-DOCE D. 2010. Bedrock controls on subglacial landform distribution and geomorphological processes: Evidence from the Late Devensian Irish Sea Ice Stream. Sedimentary Geology, 232:98-118.

PUIGDOMENECH C.G., CARVALHO B., PAIM P.S.G., FACCINI U.F. 2014. Lowstand turbidites and delta systems of the Itararé Group in the Vidal Ramos region (SC), southern Brazil. Brazilian Journal of Geology, 44:529-544.

QIE W., ALGEO T.J., LUO G., HERRMANN A. 2019. Global events of the Late Paleozoic (Early Devonian to Middle Permian): A review. Palaeogeography, Palaeoclimatology, Palaeoecology, 531(A):109259.

RAPOSO M.I.B., ESTEVES M.C.B., SANTOS P.R. 2021. Can magnetic fabric indicate the direction of a glacier movement? An example from Itararé Group and Aquidauana Formation, Paraná Basin, Brazil. Journal of South American Earth Sciences, 106:103003.

REA B.R., EVANS D.J.A. 1996. Landscapes of areal scouring in N.W. Scotland. Scottish Geographical Magazine, 112:47-50.

ROCHA-CAMPOS A.C., SANTOS P.R. 1981. The Itararé Subgroup, Aquidauana Group and San Gregório Formation, Paraná Basin, southeastern South America. In: HAMBREY M.J., HARLAND W.B. (eds) Earth's Pre-Pleistocene Glacial Record, Cambridge University Press, Cambridge, 842-852p.

ROCHA-CAMPOS A.C., MACHADO L.C.R., SANTOS P.R., CANUTO J.R., CASTRO J.C. 1988. Pavimento estriado da Glaciacão Neopaleozoica, em Alfredo Wagner, Santa Catarina, Brasil. Boletim IGUSP, 19:39-46.

ROCHA-CAMPOS A.C., SANTOS P.R., CANUTO J.R. 2008. Late Paleozoic glacial deposits of Brazil: Paraná Basin. In: FIELDING C.R., FRANK T.D., ISBELL J.L. (eds) Resolving the Late Paleozoic Ice Age in Time and Space. GSA Special Paper 441, 97-114p.

RODRIGUES M.C.N.L., TRZASKOS B., ALSOP G.I., VESELY F.F. 2020. Making a homogenite: An outcrop perspective into the evolution of deformation within mass-transport deposits. Marine and Petroleum Geology, 112:104033.

RODRIGUES M.C.N.L., TRZASKOS B., VESELY F.F., MOTTIN, T.E. 2021. Diversidade de estilos estruturais em depósitos de transporte em massa. Boletim Paranaense de Geociências, no prelo.
ROSA E.L.M. 2015. Paleogeografia da Era Glacial Neopaleozoica na porção ocidental do Gondwana: resgate e análise crítica dos dados existentes. Monografia de Conclusão de Curso, Departamento de Geologia, Universidade Federal do Paraná, 68p.

ROSAE.L.M., ISBELLJ.L. 2021. Late Paleozoic Glaciation. In: ALDERTON D., ELIAS S.A. (eds.). Encyclopedia of Geology $2^{\text {nd }}$ edition, Elsevier, 534-545p.

ROSA E.L.M., VESELY F.F., FRANÇA A.B. 2016. A review on late Paleozoic ice-related landforms in the Paraná Basin: origin and paleogeographical implications. Brazilian Journal of Geology, 46:147-166.

ROSA E.L.M., VESELY F.F., ISBELL J.L., KIPPER F., FEDORCHUK N., SOUZA P.A. 2019. Constraining the timing, kinematics and cyclicity of MississippianEarly Pennsylvanian glaciations in the Paraná Basin, Brazil. Sedimentary Geology, 384:29-49.

SANTOS P.R., ROCHA-CAMPOS A.C., CANUTO J.R. 1992. Estruturas de arrasto de icebergs em ritmito do Subgrupo Itararé (Neopaleozoico), Trombudo Central, SC. Boletim IG-USP, 23:1-18.

SANTOS P.R., ROCHA-CAMPOS A.C., CANUTO J.R. 1996. Patterns of late Paleozoic deglaciation in the Parana Basin, Brazil. Palaeogeography, Palaeoclimatology, Palaeoecology, 125:165-184.

SCHNEIDER R.L., MUHLMANN H., TOMMASI E., MEDEIROS R.A., DAEMON R.A., NOGUEIRA A.A. 1974. Revisão estratigráfica da Bacia do Paraná. SBG, $28^{\circ}$ Congresso Brasileiro de Geologia, Porto Alegre, 1, Anais, 41-65p.

SCOTESE C.R., BOUCOT A.J., MCKERROW W.S., 1999. Gondwanan palaeogeography and palaeoclimatology. Journal of African Earth Sciences, 28:99-114.

SOBIESIAK M.S., KNELLER B.,ALSOPG.I., MILANA J.P. 2018. Styles of basal interaction beneath mass transport deposits. Marine and Petroleum Geology, 98:629-639.

SOUZA P.A., BOARDMAN D.R., PREMAOR E., FÉLIX C.M., BENDER R.R., OLIVEIRA E.J. 2021. The Vittatina costabilis Zone revisited: New characterization and implications on the PennsylvanianPermian icehouse-to-greenhouse turnover in the Paraná Basin, Western Gondwana. Journal of South American Earth Sciences, 106:102968.

SUGDEN D.E. 1978. Glacial erosion by the Laurentide Ice Sheet. Journal of Glaciology, 20(83):367-391.

TEDESCO J., CAGLIARI J., COUTINHO J.R., LOPES R.C., LAVINA E.L.C. 2016. Late Paleozoic paleofjord in the southernmost Parana Basin (Brazil): Geomorphology and sedimentary fill. Geomorphology, 269:203-214.

TEDESCO J., CAGLIARI J., CHEMALE JR F., GIRELLI T., LANA C. 2019. Provenance and paleogeography of the Southern Paraná Basin: Geochemistry and $\mathrm{U}-\mathrm{Pb}$ zircon geochronology of the Carboniferous-Permian transition. Sedimentary Geology, 393-394:105539. 
TOMAZELLI L.J., SOLIANI JR. E. 1982. Evidências de atividade glacial no Paleozoico Superior do Rio Grande do Sul. SBG, $32^{\circ}$ Congresso Brasileiro de Geologia, 4, Anais, 1378-1391p.

TOMAZELLI L.J., SOLIANI JR. E. 1997. Sedimentary Facies and Depositional Environments Related to Gondwana Glaciation in Batovi and Suspiro Regions, Rio Grande do Sul, Brazil. Journal of South American Earth Sciences, 10:295-303.

TROSDTORF I., ASSINE M.L., VESELY F.F., ROCHACAMPOS A.C., SANTOS P.R., TOMIO A. 2005a. Glacially striated, soft sediment surfaces on late Paleozoic tillite at São Luiz do Purunã, PR. Anais da Academia Brasileira de Ciências, 77:367-378.

TROSDTORF I., ROCHA-CAMPOS A.C., SANTOS P.R., TOMIO A. 2005b. Origin of Late Paleozoic, multiple, glacially striated surfaces in northern Paraná Basin (Brazil): Some implications for the dynamics of the Paraná glacial lobe. Sedimentary Geology, 181:59-71.

VALDEZ V.B., AQUINO C.D., PAIM P.S.G., SOUZA P.A., MORI A.L., FALLGATTER C., MILANA J.P., KNELLER B. 2019. Late Paleozoic glacial cycles and subcycles in western Gondwana: Correlation of surface and subsurface data of the Paraná Basin, Brazil. Palaeogeography, Palaeoclimatology, Palaeoecology, 531(B):108435.

VAN DER MEER J.J.M. 1997. Short-lived streamlined bedforms (annual small flutes) formed under clean ice, Turtmann Glacier, Switzerland. Sedimentary Geology, 111:107-118.

VAN DER MEER J.J.M., MENZIES J., ROSE J. 2003. Subglacial till: the deforming glacier bed. Quaternary Science Reviews

VEEVERS J.J., POWELL M. 1987. Late Paleozoic glacial episodes in Gondwanaland reflected in transgressive- regressive depositional sequences in Euramerica. GSA Bulletin, 98:475-487.

VESELY F.F. 2006. Dinâmica sedimentar e arquitetura estratigráfica do Grupo Itararé (CarboníferoPermiano) no centro-leste da Bacia do Paraná. Tese de Doutorado, Departamento de Geologia, Universidade Federal do Paraná, 226p.
VESELY F.F., ASSINE M.L. 2002. Superfícies estriadas em arenitos do Grupo Itararé produzidas por gelo flutuante, sudeste do estado do Paraná. Revista Brasileira de Geociências, 32:587-594.

VESELY F.F., ASSINE M.L. 2006. Deglaciation sequences in the Permo-Carboniferous Itarare Group Paraná Basin, southern Brazil. Journal of South American Earth Sciences, 22:56-168.

VESELY F.F., ASSINE M.L. 2014. Ice-keel scour marks in the geological record: evidence from carboniferous soft-sediment striated surfaces in the Parana Basin, southern Brazil. Journal of Sedimentary Research, 84:26-39.

VESELY F.F., TRZASKOS B., KIPPER F., ASSINE M.L., SOUZA P.A. 2015. Sedimentary record of a fluctuating ice margin from the Pennsylvanian of western Gondwana: Paraná Basin, southern Brazil. Sedimentary Geology, 326:45-63.

VESELY F.F., RODRIGUES M.C.L.N, ROSA E.L.M., AMATO J.A., TRZASKOS B., ISBELL J., FEDORCHUK N.D. 2018. Recurrent emplacement of non-glacial diamictite during the late Paleozoic ice age. Geology, 46:615-618.

VISSER J.N.J. 1997. Deglaciation sequences in PermoCarboniferous Karoo and Kalahari basins of southern Africa: a tool in the analysis of cyclic glaciomarine basin fills. Sedimentology, 44:507-521.

VISSER J.N.J., COLLISTON W.P., TERBLANCHE J.C. 1984. The origin of soft-sediment deformation structures in Permo-Carboniferous glacial and proglacial beds, South Africa. Journal of Sedimentary Petrology, 54(4):1183-1196

WHITE I.C. 1908. Relatório sobre as Coal Measures e rochas associadas no sul do Brasil. Comissão de Estudos das Minas de Carvão de Pedra, Rio de Janeiro, Relatório Final.

WOODWORTH-LYNAS C.M.T., DOWDESWELL J.D. 1994. Soft-sediment striated surfaces and massive diamicton facies produced by floating ice. In: DEYNOUX M., MILLER J.M.J., DOMACK E.W., EYLES N., FAIRCHILD I.J., YOUNG G.M. (eds) Earth's Glacial Record. Cambridge University Press, Cambridge, 241-259p. 